\title{
LOS CRIADOS SALMANTINOS DURANTE EL SIGLO XVII (1601-1650): LAS CONDICIONES LABORALES'
}

\author{
Francisco Javier Lorenzo Pinar \\ Universidad de Salamanca
}

\begin{abstract}
RESUmen. El presente artículo trata de aproximarnos a las condiciones laborales de los criados, fundamentalmente domésticos, de la urbe salmantina a través de los contratos y de los testamentos conservados en los protocolos notariales. Se abordan aspectos como la diversidad de labores a realizar, la duración de los convenios, los salarios o compensaciones recibidas a cambio del trabajo, las penalizaciones por abandonarlo, los motivos de rescisión o las relaciones amo-criado en el ámbito de sus tareas.
\end{abstract}

Palabras clave: criado, servicio doméstico, contratos, Salamanca, España, siglo XVII.

\begin{abstract}
The present article tries to approach us to the domestic servants labour conditions in Salamanca city -in the west of Spain- through the contracts and the testaments that can be found in the notarial documents. We handle aspects as the diversity of tasks to realize, the contracts duration, the penalizations for abandoning them, the cancellation motives or the relation between servants and masters within the limits of the job.
\end{abstract}

Keywords: domestic urban servants, contracts, Salamanca, Spain, Seventeenth Century.

\section{Vinculación laboral y documentación}

El conocimiento de la actividad laboral de los criados en esta primera mitad del siglo XVII está plagado de dificultades, unas veces por los silencios documentales y otras por las limitaciones de las mismas fuentes. La documentación utilizada en este

1 Trabajo recibido el 13/07/2007 y aceptado para su publicación el 2/11/2007.

El presente artículo constituye la primera parte de trabajo conjunto sobre esta temática. El otro llevará por título: "Los criados salmantinos en el siglo XVII (1600-1650): Conflictividad social y actitudes ante la muerte" (II). Studia Historica. Historia Moderna (En prensa). 
trabajo -187 cartas de asiento de mozo/a de soldada o servicio, 112 testamentos conservados en los protocolos notariales del Archivo Histórico Provincial salmantino, además de los pleitos incoados ante el Tribunal Diocesano de la ciudad-, procedente del vaciado completo de estos fondos, no muestran más que una realidad parcial de lo que pudieron ser las condiciones de trabajo de este sector. Lamentablemente, los protocolos notariales no suelen registrar todas las vinculaciones contractuales efectuadas por los criados. Las últimas voluntades de éstos nos ofrecen testimonios de relaciones de servicio sin firmarse acuerdos previos. Es el caso, entre otros, de Francisca Tejeda quien declaraba en su testamento que llevaba doce o trece años en casa de su señora y en "... este tiempo no hubo conçierto ninguno de su salario, mas que mi señora me ha pagado cada año en dinero y bestidos que me ha dado y otras cosas más paga de lo que me podía dar por salario"2. La formalización de un contrato podía incluso establecerse en situaciones extremas como era en la misma redacción del testamento, hecho que se percibe en Juana Rodríguez, ama del licenciado José Lozano, clérigo. Tras aproximadamente año y medio de servicio, afirmaba en su última voluntad: “... no teníamos fecho conçierto y ahora que su merced está presente nos convenimos a seis ducados por año..." . Otras veces los asientos de las mozas de servicio se concretaron tras un período previo de trabajo, regulado simplemente por un acuerdo verbal entre partes ${ }^{4}$. No se trató de un fenómeno exclusivamente salmantino. J. P. Gutton indica para el caso francés que bastaba una simple mención en el libro de razón donde se registrase el salario del criado para considerarlo como contratado. También G. K. Brunelle habla de una mayoría de contratos orales entre criadas y señoras para Nantes en el siglo $\mathrm{XVI}$, los cuales estuvieron regulados por normas escritas y convenciones ampliamente sostenidas que marcaban los derechos y los deberes de ambas partes ${ }^{5}$. Isidro Dubert constata para el ámbito rural gallego de finales del Antiguo Régimen el carácter verbal de unas contrataciones que se renovaban de manera automática cada año ${ }^{6}$.

Por otro lado, el contraste de la información de los asientos de mozas de servicio con los testamentos, las escrituras de protesta, las de apartamiento, las de poder o las de dote -entre otras muchas- nos permite apreciar alusiones a múltiples criadas y criados de quienes no se ha conservado ningún tipo de contrato por escrito. Tampoco

2 Archivo Histórico Provincial de Salamanca (en adelante A.H.P.Sa.). Protocolos Notariales (en adelante P.N.). Legajo. (en adelante Leg.) 3507. 7-I-1617. Fols. 2058-2059.

3 A.H.P.Sa. P.N. Leg. 4719. 21-X-1635. Fols. 44-45.

4 A.H.P.Sa. P.N. Leg. 4328. 18-VIII-1608. Fols. 284-285.

5 BRUNELLE, G. K.: "Contractual Kin: Servants and their Mistresses in Sixteenth-Century Nantes”, Journal of Early Modern History, II, 1998, pp. 374 y 377.

6 DUBERT, I.: "Criados, estructura económica y social y mercado de trabajo en Galicia rural a finales del Antiguo Régimen”, Historia Agraria. Revista de Agricultura e Historia Rural, 35, 2005, p. 10; GUTTON, J. P.: Domestiques et serviteurs dans la France de l'Ancien Régime, París, Aubier Montaigne, 1981, p. 69. 
son muchos los que han pervivido de los realizados por los nobles o individuos calificados de don, para quienes, a tenor de algunos testimonios de la época, era inherente a su categoría social la posesión de criados, como se deduce asimismo de algunas declaraciones de miembros de este sector ${ }^{7}$. Estudios sobre la aristocracia española, caso del de Adolfo Carrasco, han subrayado que el rodearse de una abundante y variada servidumbre era un aspecto primordial del modo de vida noble ${ }^{8}$. Cissie Fairchilds apunta que en el Antiguo Régimen el empleo de al menos un criado era el baremo mínimo de aquéllos que clamaban un estatus noble 9 .

Como se puede apreciar, a tenor de las carencias subrayadas, resulta imposible conocer el volumen exacto de los sirvientes existentes en la urbe salmantina en este período a través de los contratos laborales realizados ante escribano dado que parte de ellos se efectuaron sin mediar documento alguno ${ }^{10}$. Por otro lado carecemos de censos para esta época, relativos a la urbe salmantina, que nos permitan calibrar no sólo el volumen de este tipo de trabajadores sino también su porcentaje dentro de la población activa del momento. Las referencias más cercanas las obtenemos de los datos conservados en la segunda mitad del siglo XVI. Según el censo de 1561 para una población de 4.734 vecinos el mundo del servicio suponía el 21,64 por ciento del sector terciario y el 9,31 por ciento de la población activa -entre quienes indicaron su profesión-, porcentaje éste último que bajó al 2,9 en $1598^{11}$.

7 Don Miguel de Meneses y Zúñiga, quien había consumido en sus estudios, pretensiones y gastos de su casa toda su hacienda, alegaba que por sus muchas deudas carecía del sustento necesario para poder vivir y andaba con hávito pobre y menos deçente del que su calidad requería, y sin tener un criado que le sirviese ni acompañase. A.H.P.Sa. P.N. Leg. 5151. 1628. Fols. 493-520.

8 La presencia de numerosos criados, junto con ricos trajes, joyas, coches, caballos, vivienda y muebles, entran a formar parte del conglomerado de posesiones que respondían al lema: nobleza obliga.. CARRASCO MARTÍNEZ, A.: "Señores y criados. La servidumbre de la aristocracia en el siglo XVIII”, en ÁLVAREZ SANTALÓ, L. C. y CREMADES GRIÑÁN, C. Mª : Mentalidad e ideología en el Antiguo Régimen. II Reunión Cientifica de la Asociación Española de Historia Moderna, vol. II, Murcia, Universidad de Murcia, 1992, p. 203; ÁLVAREZ-OSORIO ALVARIÑO, A.: "Rango y apariencia: el decoro y la quiebra de la distinción en Castilla (siglos XVI-XVIII)", Anales de la Universidad de Alicante, 17, 1998-1999, p. 265.

9 Raffaella Sarti cita varias obras de la Edad Moderna donde se menciona la conveniencia de tener un buen número de criados para vivir como un gran gentilhombre. Éstos constituían un "signo" de la posición social del amo. En el siglo XVIII se levantaron voces críticas contra este tipo de vanidades. FAIRCHILDS, C.: Domestic enemies. Servants and their Masters in Old Regime France, Baltimore/ Londres, The Johns Hopkins University Press, 1984, p. 11; SARTI, R.: "Comparir <con equipaggio in scena> personale domestico e prestigio nobiliare (Bologna, fine XVII-I inizio XX Secolo", Cheiron, 3132, 1999, pp. 135-136, 140 у 160.

10 DUBERT, I.: “Criados, estructura económica y social y mercado de trabajo...”, Op. cit., p. 10; GUTTON, J. P. Op. cit., p. 69.

11 Hemos de tener en cuenta que en el censo de 1561 el 54,29\% de las personas no indicó su profesión y en el de 1598 el 78,53 por ciento. El servicio doméstico estaba compuesto en la primera fecha por 204 individuos, cifra que disminuyó a 121 en 1598 para un total de 4.109 vecinos. Por otro 


\section{El concepto de criado}

Aunque nos centraremos fundamentalmente en los individuos que realizaron un trabajo doméstico en la urbe salmantina, tanto particulares como instituciones utilizaron los vocablos moza de soldada, de servicio y criado de una manera amplia para referirse, principalmente, a mujeres y hombres dedicados a tareas que sobrepasaron las meras labores del hogar -no siempre fáciles de concretar- ${ }^{12}$. Así por ejemplo, en los asientos de jóvenes con fruteros, éstos últimos habitualmente se comprometían a servirles vendiendo fruta por las calles de la ciudad, “... acudiendo a su casa y tienda; en lo tocante al oficio de tal frutero y demás que le mandare, como a su criado..."13. Lo mismo podemos afirmar respecto a otras profesiones como carreteros o estudiantes que quedaban a merced de sus amos en cuanto a las tareas que les asignasen ${ }^{14}$. Se constata en todos estos casos que los salarios de estos jóvenes sobrepasaron la media percibida por los criados dedicados exclusivamente a labores domésticas, justificable en parte ya que sus tareas eran más diversificadas e incluso requerían, caso de los criados de los boticarios, cierta cualificación -conocimiento de lectura, escritura y latín-15.

Entre los sirvientes de la nobleza y de individuos con la categoría de don hallamos una amplia gama de criados que desarrollaron variedad de tareas, algunas de ellas ajenas al trabajo del hogar, como la enseñanza de la doctrina cristiana y de labor, o actuaron simplemente como acompañantes ${ }^{16}$. En los contratos salmantinos aparecen también pajes, quienes a veces tan sólo percibieron el vestido y el calzado por

lado, quienes han estudiado estos censos señalan que el servicio doméstico y el asalariado aparecen infravalorados en estos cómputos ya que la mujer apenas representó el 10,4 por ciento, porcentaje que contrasta con lo sucedido en el siglo XVII donde la presencia femenina, según contratos y testamentos, fue mayoritaria en el servicio doméstico urbano. DÍAZ MEDINA, A.: "Estructura demográfica y socioprofesional en Salamanca en 1561", Provincia de Salamanca. Revista de Estudios, n 4, 1982, pp. 69-100; VELA SANTAMARÍA, F. J.: "Salamanca en la época de Felipe II", en Pasado histórico de Castilla y León. I Congreso de Castilla y León, Burgos, Junta de Castilla y León, 1983, pp. 281-323.

12 Gregorio Salinero apunta que el término criado no era suficiente para identificar al servicio doméstico y que incluso el concepto servicio se aplicaba a una realidad amplia que sobrepasaba tal esfera. SALINERO, G. : "Maîtres et domestiques de Trujillo. La depéndance domestique dans une ville royale au temps de Philippe II", en MARTÍNEZ RUIZ, E. (dir.). : Madrid, Felipe II y las ciudades de la Monarquía. Las ciudades: vida y cultura, tomo III, Madrid, Actas, 2000, p. 111.

13 Solían percibir a cambio la comida y un salario de entre 88 y 100 reales anuales, además de las suelas que necesitasen para sus zapatos. A.H.P.Sa. P.N. Leg. 3270. 31-I-1629. Fol. 432; A.H.P.Sa. P.N. Leg. 5148. 13-XII-1618. Fol. 768. A.H.P.Sa. P.N. Leg. 3735. 10-VIII-1602. Fols. 139-140; Leg. 5891. 5IV-1641. Fol. 1220; Leg. 3553. 5-VI-1648. Fols. 2078; Leg. 4177. 13-VI-1617. Fol. 624; Leg. 3684. 22X-1633. Fol. 509; Leg. 3266. 20-IV-1617.

14 A.H.P.Sa. P.N. Leg. 3885. 14-XI-1602. Fols. 87-88.

15 A.H.P.Sa. P.N. Leg. 3885. 17-XI-1602. Fols. 85-86.

16 A.H.P.Sa. Leg. 5274. Fols. 1004-1005. 
su trabajo ${ }^{17}$; dueñas y doncellas ${ }^{18}$; escuderos que se obligaban a acompañar a diario con puntualidad tanto a los señores como a sus esposas e incluso podían intervenir como cobradores de sus rentas a través de poderes ${ }^{19}$; mozos de caballos $^{20}$; lacayos ${ }^{21}$; guardarropas ${ }^{22}$; cocineros-despenseros $^{23}$; maestresalas ${ }^{24}$ y mayordomos, entre otros ${ }^{25}$.

También apreciamos cómo algunos documentos referidos a los aprendices de los artesanos y de otros ámbitos profesionales recibieron el título de carta de solda-

17 En algún documento se especifica que servirían en todo lo demás que le mandare que sea lízito y honesto a él de mandar. Recibían entre 11 y 14 reales mensuales además de dos libras de pan, y entre 12 y 16 maravedíes diarios de ración. En el caso de entregárseles librea se les descontaba del sueldo. Podía exigírseles la presentación de fiadores. A.H.P.Sa. P.N. Leg. 4245. 16-III-1606. Fols. 253; Leg. 4344. 23VI-1621. Fols. 794-795; Leg. 3535. 18-III-1634. Fol. 914.

18 Alicia Fernández indica que las dueñas de los señores de título debían ser mujeres viudas o de edad avanzada. A su cargo estaban las doncellas y criadas, la administración de las tareas domésticas y el cuidado de los niños. A.H.P.Sa. P.N. Leg. 3551. 24-VIII-1632. Fols. 1647-1648; FERNÁNDEZ PÉREZ, A.: "La mujer trabajadora del Barroco a través de la picaresca", en VV.AA.: El trabajo de las mujeres: siglos XVI-XIX. VI Jornadas de Investigación Interdisciplinaria sobre la mujer, Madrid, Universidad Autónoma, 1987, p. 4.

19 Los salarios de los escuderos solían ser más elevados que los de los mozos de soldada domésticos. Andrés de Vallesa, al servicio de doña Ana Gasco de Herrera, percibía 2,5 reales diarios en concepto de ración - cobrados diaria o semanalmente, como él desease-. Si salía fuera de Salamanca el salario se elevaba a 8 reales diarios, además de proporcionársele las cabalgaduras. A.H.P.Sa. Leg. 4358. 20-IV-1628. Fols. 286-287.

20 Juan Fernández sirvió a don Luis de Castillo Portocarrero de mozo de caballos a razón de 20 maravedíes y dos libras de pan diarias de ración y 16 reales mensuales. Además se le entregó un vestido, la mitad de baldado -gratis-y la otra mitad a costa de la soldada. A.H.P.Sa. P.N. Leg. 3.888. 30-VI-1607. Fols. 257-258; Leg. 5470. 24-X-1616. Fol. 1067.

21 Francisco Díez, natural de Valdujo (Portugal), de 10 años de edad, se comprometió a servir de lacayo al licenciado don Miguel de Zúñiga teniendo que tratar bien a una mula y en todo lo demás que más mandare. Su salario se fijó en 110 reales anuales además de medio real y dos libras de pan de ración diaria. El número de estos lacayos o mozos de espuelas estuvo limitado a dos en el siglo XVI, ampliándose a cuatro en la siguiente centuria, aunque sólo para los Grandes. A.H.P.Sa. P.N. Leg. 5282. 29-X-1613. Fol. 1021; Leg. 5471. 20-XII-1617. Fols. 796-797; Recopilación de las leyes destos Reynos (Nueva Recopilación de Leyes), Madrid, Catalina de Barrio y Angulo y Diego de la Carrera, 1640, Lib. VI, Tit. XX, Ley I, fol. 196.

22 Martín García, guardarropa y tapicero del Duque de Béjar, se encargaba de custodiar las colgaduras, tapicerías, sedas, camas, alfombras, estrados, doseles, bufetes, bancos, braseros, pabellones, colchones, cobertores de camas, tablas de pinturas que adornaban los aposentos, galas de la dicha casa y el ajuar de ropa, excepto la plata. Ofreció dos fiadores para ello. Leg. 4251. 4-XI-1621. Fols. 167-168.

23 Alonso Gil fue contratado por don Juan Alonso de Solís, clérigo presbítero, como cocinero y despensero por un salario de 1.320 reales anuales, uno de los más elevados. A.H.P.Sa. P.N. Leg. 3.500. 28IX-1612. Fols. 892-896; Leg. 4715. 20-X-1631. Fols. 102-104.

24 Juan Mayano Díez, demandó a los herederos del obispo salmantino don Pedro Junco de Posada alegando que le sirvió durante 19 años de paje, caballerizo y maestresala aduciendo que cada año había merecido muy bien cien ducados por ser honbre gran serbiçial y de cuidado de su ofiçio. Indica que cuando trabajó como su caballerizo se le señalaron 24.000 maravedíes de salario, aposento, cama y un real de ración y dos libras de pan cada día, además de un paje para que le sirviese. A.H.D. Sa. Leg. 3-65. 9-VIII-1602.

25 Leg. 5011. 7-I-1631. Fols. 1354-1359; Leg. 4716. 3-VIII-1632. Fol. 414. 
da o de asiento -denominación propia de contratos de los criados-; e incluso alguno aparece con el encabezamiento de carta de aprendiz del criado de... y a continuación el nombre del maestro, lo que nos hace sospechar que estos jóvenes fueron utilizados igualmente para labores domésticas, tal y como sucedió en otros lugares de la geografía española ${ }^{26}$. José Damián González subraya también cómo las categorías laborales inferiores de asalariados no agremiados se designaban a veces como criados $^{27}$. Florentino López menciona, para Asturias durante el siglo XVIII, que los aprendices vivían una situación próxima a la de criados al igual que sucedió en Inglaterra ${ }^{28}$.

En otras profesiones, algunas de ellas no artesanales, caso de los aguadores, se contrataron igualmente muchachos, en condiciones similares a las de los criados domésticos, para servir a soldada acarreando agua y obligados a todo lo que se les mandare $^{29}$. Lo mismo se aprecia entre los tratantes de cuchillería y joyería o entre los destiladores $^{30}$. Varios estudiantes de la Universidad salmantina compatibilizaron sus

26 En la urbe de Toro, en el siglo XVI, ejercieron labores propias de criados como cavar en las viñas de sus maestros, segar sus campos de trigo, ir por agua al río, vender sus mercancías en la plaza o ayudar a sus mujeres en casa. A.H.P.Sa. P.N. Leg. 5089. 23-V-1601. Fols. 323-324; Leg. 4254. 11-VII-1628. Fol. 57; Leg.4252. 26-I-1623. Fol. 162 (antiguo 153); Véase LORENZO PINAR, F. J.: El aprendizaje de los oficios artesanos en Toro en el siglo XVI, Zamora, Instituto de Estudios Zamoranos Florián de Ocampo, 2007 (en prensa).

27 Marta Vicente subraya el fenómeno inverso de los criados usados como aprendices en Barcelona en el siglo XVIII por serle a los maestros más cómodo mantener una mujer a título de criada que satisfacer los jornales que debería pagar a un mancebo práctico. También Juan Carlos Zofío afirma que algunas criadas madrileñas realizaban ciertas tareas en el taller y que en la era preindustrial no existía una estricta separación entre las labores de un criado doméstico y las de un aprendiz. Lo mismo sucedía en Zaragoza. En el siglo XVIII en algunos contratos de aprendiz aparece claramente la obligación de éste de servir como criado o doméstico. GONZÁLEZ ARCE, J. D.: Gremios, producción artesanal y mercado, Murcia, Universidad de Murcia, 2000, p. 98; VICENTE VALENTÍN, M.: "El treball de la dona dins els gremis a la Barcelona del segle XVIII (una aproximació)”, Pedralbes, 8-I, 1988, p. 269; ZOFÍO LLORENTE, J. C.: “Trabajo y socialización. Los aprendices en Madrid durante la segunda mitad del siglo XVI", en MARTÍNEZ RUIZ, E. (dir.).: Felipe II y las ciudades de la Monarquí. Capitalismo y Economía, vol. II, Madrid, Actas, 2000, p. 529 y Gremios y artesanos en Madrid. 1550-1650. La sociedad del trabajo en una ciudad cortesana preindustria, Madrid, CSIC, 2005, p. 438; MORAL RONCAL, A. M.: Gremios e Ilustración en Madrid (1775-1836), Madrid, Actas, 1998, p. 134 y RAMIRO MOYA, F. J.: "Mujer y trabajo en los gremios de la Zaragoza del Antiguo Régimen", Revista de Historia Jerónimo de Zurita, 776-777, 2001-2002, p. 166.

28 Fuera del ámbito español Carolyn Steedman igualmente indica cómo algunos aprendices fueron utilizados por sus amos y amas para realizar tareas domésticas convirtiéndose así en una especie de sirvientes de la casa. LÓPEZ IGLESIAS, F.: "Los criados en la Asturias del Antiguo Régimen”, Boletín del Instituto de Estudios Asturianos, 150, 1997, p. 171; STEEDMAN, C.: "Servicio doméstico y servidumbre en el mundo del trabajo: los criados en Inglaterra, 1750-1820", en PANIAGUA, J., PIQUERAS, J. A. y SANZ, V. (eds.).: Cultura social y politica en el mundo del trabajo, Valencia, Centro Tomás y Valiente, 1999 , p. 106.

29 A.H.P.Sa. Leg. 3500. 27-VI-1612. Fol. 1065.

30 A.H.P.Sa. P.N. Leg. 3900. 24-IX-1635. Fols. 833-834; Leg. 4724. 28-III-1640. Fols. 870-871; Leg. 3535. 24-VII-1634. Fol. 806. 
estudios con el mundo del servicio ${ }^{31}$. Incluso algún hidalgo aparece como criado de la alta nobleza o del tercer estado por la situación de orfandad o precariedad en la que había quedado sumido, circunstancia que no fue ajena a otras ciudades españolas, caso de Madrid, como apunta Pilar Tenorio ${ }^{32}$.

En el mundo rural también aparecen estas cartas de asiento de mozo con características similares a las de la urbe. Los jóvenes se ponían a servir en el oficio de labrador a cambio de tenerlos el amo en su casa dándoles de comer, beber, cama y ropa lavada y un salario que podía superar los 100 reales anuales -hasta 132-33. Es el caso de los mozos de la huerta, quienes además de trabajar como hortelanos, podían ser obligados a acudir “... a cualquier otra cosa que por [sus amos] les fuere mandado, con toda puntualidad..." 34 . Se trata de una situación similar a la apuntada por Chris Middelton para Inglaterra ${ }^{35}$. El salario podía llegar en estos casos a los 473 reales, bastante más elevado que en las situaciones anteriores y que el de los jornaleros del campo quienes solían percibir por día de trabajo entre 30 maravedíes y 3,5 reales, además del vino necesario para combatir la sed de la jornada laboral. En cualquier caso, el mundo de los criados no se puede contemplar como un sector homogéneo ya que ni todos cobraron el mismo salario, ni realizaron las mismas labores e incluso algunos de ellos contaron con sus propios sirvientes ${ }^{36}$.

31 A.H.P.Sa. P.N. Leg. 4100. Escritura de apartamiento de Cristóbal de Arcas, estudiante. 16I-1617. Fol. 1182; Leg. 5470. 22-X-1616. Fols. 1065-1066; Leg. 2984. 20-VIII-16311. Fol. 910. Para un estudio sobre el ámbito del servicio relacionado con familiares y porcionistas véase: CARABIAS TORRES, A.: Colegios Mayores: Centros de poder, Salamanca, Universidad de Salamanca, 1986.

32 A.H.P.Sa. P.N. Leg. 3765. Fols. 548-550; Leg. 5490. 24-VII-1630. Fols. 1278-1280; TENORIO GÓMEZ, P.: Realidad social y situación femenina en el Madrid del siglo XVII, Madrid, Universidad Complutense, 1992, p. 330.

33 En este ámbito agrario se hallan contratos de aperadores, catalogados en los documentos como criados, quienes acudían a la labranza del amo, a guardar el monte y la caza, actuaban como gañanes y hacían todo lo demás que [se] le [s] mandare. Su salario era más elevado que el de los sirvientes domésticos de la ciudad. A.H.P.Sa. P.N. Leg. 3491. 4-I-1603. Fols. 1171-1172; Leg. 5704. 24-VI-1613. Fols. 745-746; Leg 5711. 27-IV-1633. Fols. 1050-1051.

34 A.H.P.Sa. P.N. Leg. 4722. 5-XI-1638. Fol. 1174; Leg. 3261. 2-II-1624. Fols. 386-387.

35 Chris Middelton indica que la servidumbre agrícola se dedicaban más a las tareas del agro que a las labores domésticas, y estaba obligada a cualquier cosa que le encomendasen sus amos. MIDDLETON, Ch.: "El destino común de los <famula>: las divisiones de género en la historia del trabajo asalariado", en BORDERÍAS, C., CARRASCO, C. y ALEMANY, C. (comps.): Las mujeres y el trabajo. Rupturas conceptuales, Barcelona, Crítica, 1994, p. 226.

36 Además percibían dinero, comida, bebida, casa, cama y ropa lavada. Entre las labores efectuadas se habla de aderezar vallados y portillos, labrar, cavar, echar cepas, tapar y cubrirlas, meter entelada y camas, coger vides -durante el mes de abril-, podar -la labor mejor remunerada-, coger grama y combatir el pulgón - despulgonar- poniendo aceite de enebro con unos hilos alrededor de las viñas. En el caso de los guardas de ganado la soldada era similar a la de los domésticos. A.H.P.Sa. P.N. Leg. 5488. 12VII-1629. Fols. 1069-1070; Leg. 5486. Memorial de los gastos de las viñas de María de Beltrán, viuda del mercader de paños Francisco Fernández. 23-XI-1628. Fols. 734-741; Leg. 4113. Memorial de los gastos de las viñas de la memoria de Ana Robles. Año 1640. Fol. 643; Leg. 4722. 6-III-1628. Fol. 1231; Leg. 


\section{El servicio doméstico en la urbe salmantina}

\section{a) Procedencia, edad, estado civil y duración del contrato.}

Si atendemos a la evolución cronológica de los contratos firmados en la ciudad de Salamanca se aprecia cómo un tercio de ellos se realizó en la primera década del Seiscientos, una cuarta parte en la segunda y la misma proporción en la tercera década. A partir de este momento se experimenta un descenso brusco, acentuado en la década de 1640, lo cual pone de relieve la existencia de una estrecha relación entre la contratación laboral, el período bélico vivido con Portugal por estas fechas y la crisis demográfica padecida por la ciudad. Aunque desconocemos la categoría social de uno de cada tres amos contratantes, prácticamente desde todos los sectores se demandaron criados, especialmente entre los fruteros, los individuos con el calificativo de don, mercaderes, procuradores y mesoneros, por este orden ${ }^{37}$. Raramente -sólo en cinco casos- entraron a servir a algún miembro de la propia familia.

Los criados procedieron casi por iguales partes del ámbito urbano y del rural. Seis de cada diez provenían de la misma provincia de Salamanca; ocho de cada cien de Galicia o de Portugal ${ }^{38}$; un tres por ciento vinieron de Zamora y el resto de León, Aragón y Francia, o no especificaron su origen. Eran analfabetos en su inmensa mayoría -sólo 13 de ellos firmaron sus contratos-. Prevalecieron las jóvenes huérfanas y solteras - al menos dos tercios de los contratados, el otro tercio no determina su situación civil-. Si tenemos en cuenta los testamentos efectuados por los criados esta cifra ascendería al 71 por ciento. La presencia mayoritaria de mujeres frente a los varones en el ámbito del servicio doméstico aparece en lugares como Murcia entre los eclesiásticos -estuvieron trabajando en al menos el 62\% de sus hogares, si se incluyen las ama. En algunas zonas de Italia, caso de Venecia, las mujeres supusieron a principios del siglo XVII el 70,4 por ciento de los criados y a mediados de este siglo el 64,1 por ciento. En parte de Escocia las criadas superaron en una proporción de 3 a 2 a los varones en 1636; en Varsovia se elevaban hasta el 83 por ciento. Esta tendencia

4374. Año 1637. Fols. 350-351; Leg. 3674. Año 1607. Salarios de los sirvientes que el doctor Gil poseía en Buenalbarba. Fol. 702 r; Leg. 4713. 13-IX-1629. Fols. 1048-1051; Leg. 5488. Año 1629. Fol.471; Leg. 4010. 1630. Fols. 474-476; Leg. 5492. 11-II-1631. Memoria de las labranzas de María Beltrán.

37 En Madrid el 45,9\% de quienes contrataron criadas fueron artesanos. ZOFÍO LLORENTE, J. C.: Op. cit., p. 439.

38 No todo el que procedió del país luso y vino a Salamanca a servir firmó un contrato aunque tuviese una corta edad. A través de las licencias matrimoniales se aprecian varios casos, como el de María Domínguez, natural de Buró (Braga), quien, cuando llegó a la urbe con 12 años de edad entró al servicio de Antonio González sin mediar documentos; o, el de María Hernández, de la villa de Barcos (Lamego), quien siendo muy pequeña -de 11 años de edad- se puso como criada del mesonero del estudio Pedro Rodríguez en las mismas condiciones. A.H.P.Sa. P.N. Leg. 39-159. 31-VIII-1638; Leg. 40-173. Año 1639. 
se percibe también en el siglo XVIII para otros lugares. En Francia la cifra de féminas estaba en un 60 por ciento del sector; en Galicia entre el 64 y el 78 por ciento de los criados urbanos fueron mujeres, cifra más elevada en Valencia donde llegaron al $80,4 \%$. Sin embargo, en Roma en esta misma centuria se constata un claro predominio de los varones -más de la mitad del servicio fueron hombres casados-. A tenor de las afirmaciones de Ofelia Rey, la verdadera distinción social la aportaba el servicio doméstico masculino predominante en las casas más acomodadas ${ }^{39}$.

Las mozas salmantinas se hallaban habitualmente bajo la autoridad de un curador a la hora de ser contratadas ${ }^{40}$ - en la mitad de las situaciones, frente a una tercera parte que no señala nada al respecto-, generalmente procuradores del número nombrados para tal efecto lo cual imposibilita el conocimiento de sus datos de filiación.

39 IRIGOYEN LÓPEZ, A.: "Análisis de los hogares eclesiásticos en Murcia durante el siglo XVII”, en CHACÓN JIMÉNEZ, F. y FERRER i ALÓS, Ll.: Familia, casa y trabajo. Historia de la Familia, una nueva perspectiva sobre la sociedad europea, Murcia, Universidad de Murcia, 1997, p. 189; MOLIN, G. da: "Family Forms and Domestic Service in Southern Italy from the Seventeenth to the Nineteenth Centuries", Journal of Family History, 15-4, 1990, p. 518 y "Struttura della famiglia e personale di servizio nell'Italia meridionale”, en BARBAGLI, M. y KERTZER, D. I.: Storia della famiglia italiana. 1750-1950, Bolonia, Il Mulino, 1992, p. 242; ARRU, A.: Il servo. Storia di una carriera nel Settecento, Bolonia, Il Mulino, 1995, p. 28; REY CASTELAO, O.: "Mujer y sociedad en la Galicia del Antiguo Régimen”, Obradoiro de Historia Moderna, 3, 1994, p. 68; MIKELARENA, F.: Demografía y familia en la Navarra tradicional, Pamplona, Gobierno de Navarra, 1995, p. 304; DUBERT, I.: Historia de la familia en Galicia durante la Época Moderna. 1550-1830, A Coruña, Edicios do Castro, 1992, p. 137 y "Domestic service and social modernization in urban Galicia, 1752-1920", Continuity and Change, 14, 1999, p. 218; SAAVEDRA, P.: La vida cotidiana en la Galicia del Antiguo Régimen, Barcelona, Crítica, 1994, p. 246; RIAL GARCÍA, S.: Las mujeres en la economía urbana del Antiguo Régimen: Santiago durante el siglo XVIII, A Coruña, Edicios do Castro, 1995; "El servicio doméstico: una vía laboral para las mujeres en Santiago de Compostela a finales del Antiguo Régimen", en RAMOS, Mª D. y VERA, Ma . T. (eds.): $E l$ trabajo de las mujeres. Pasado y presente, tomo III, Málaga, Diputación de Málaga, 1996, p. 315 y "Las mujeres < solas> en la sociedad semi-urbana gallega del siglo XVIII", Obradoiro de Historia Moderna, 8 , 1999, p. 186; GUTTON, J. P. Op. cit., p. 73; ROMANO, D.: Housecraft and statecraft. Domestic service in Renaissance Venice, 1400-1600, Baltimore, The Johns Hopkins University Press, 1996, p. 109; EWAN, E.: "Mistresses of Themselves? Female Domestic Servants and By-Employments in Sixteenth Century Scottish Towns", en FAUVE-CHAMOUX, A. (ed.): Domestic Service and the Formation of European Identity. Understanding the Globalization of Domestic Work, $16^{\text {th }}$ and $21^{\text {st }}$ centuries, Londres, Tate, 2004, p. 413; KUKLO, C. y KAMECKA, M.: "Ser sirviente en una familia polaca de los siglos XVI al XX. Evolución del estatus social y material de los criados", Obradoiro de Historia Moderna, 11, 2002, p. 122; DÍEZ, F.: Viles y mecánicos. Trabajo y sociedad en la Valencia preindustrial, Valencia, Edicions Alfons el Magnánim, 1990, p. 155

40 En Madrid existieron agentes de colocación -padres de mozas- de criadas que solían acomodarlas a cambio de dinero. Lo mismo sucedió en otros lugares de Europa, caso de Nuremberg. En Salamanca sólo hemos encontrado una alusión a este personaje. A.H.P.Sa. P.N. Leg. 4883. 3-VI-1613. Fols. 844-845; Leg. 3520. 18-IX-1626. Fols. 1142; BRAVO LOZANO, J.: "Fuentes para el estudio del trabajo femenino en la Edad Moderna. El caso de Madrid a fines del siglo XVII", en VV.AA.: El trabajo de las mujeres...Op. cit., p. 21; WIESER, M. E.: “¿Buhoneras insignificantes o mercaderes esenciales?. Las mujeres, el comercio y los servicios en Nuremberg durante la Edad Moderna", en AMELANG, J.S. y NASH, M.: Historia y género: las mujeres en la Europa Moderna y Contemporánea, Valencia, Edicions Alfons el Magnànim, 1990, p. 178. 
Tan sólo un 7 por ciento de ellas habían superado la mayoría de edad -veinticinco años- y el resto oscilaba entre los seis y los veinte años, siendo la edad modal la de diecisiete años. La mayor concentración de mujeres que entraron como criadas se produjo entre los 15 y los 25 años. En este sentido no difiere en gran medida de otros modelos europeos en los cuales los menores de 15 años no solían representar más allá del $10 \%$ de todos los criados ${ }^{41}$.

La edad más temprana a la que la mujer se inició en el mundo del servicio en la ciudad salmantina fue la de seis años -si no incluimos las situaciones en las que las niñas eran dadas a criar a otra persona para que las sirviera- ${ }^{42}$. Entre éstas últimas cabe subrayar el caso de María Moríñigo, huérfana de madre, recibida “... por amor de Nuestro Señor...” por parte de Martín Hernández, vecino de Arcediano, a la edad de catorce meses. Se comprometió a darla de comer, vestir y calzar "... sin llevarla cosa alguna, y ni a él tanpoco se le ha de pedir salario ninguno del tiempo que la tubiese...”. Cuando se casase la joven le daría “... su casa alhajada y una cama de ropas según se acostumbra en dicho lugar a semejantes personas...”. Además, el padre no la podría “... quitar de su serviçio e casa a la dicha su hixa fasta que se cas[as]e con pena que si lo hiçiere le ha de pagar todo aquello que le hubiere alimentado y dado de bestir, y además de eso çinqüenta ducados para la lunbre del Santísimo Sacramento

41 Esta tendencia es similar a la observada para períodos históricos anteriores -siglo XV-. COLLANTES DE TERÁN SÁNCHEZ, A. de : "L'apprenti dans l'Espagne Médiévale", Razo, (Chaiers du Centre d'Études Médiévales de Nice), 14, Universidad de Niza, 1993, p. 92 ; FAUVE-CHAMOUX, A. Y WALL, R : «Introduction », en Domestic servants in comparative perspective. History of family, 10. 2005 , p. 346.

42 Desde la Baja Edad Media se prohijaron niñas -en Córdoba desde entre dos y seis años de edad- para ayudar a la nueva madre como una hija pero también como una criada. En Valencia, las niñas de las familias más modestas se iniciaban entre los 8 y 10 años. En el Alto Palancia a los 8 años. En Granada se mencionan niñas de hasta 3 años de edad. En Bilbao, Sevilla y en otras zonas de la Corona de Castilla se observa la misma tendencia aunque los estudios no indican edades. PÁEZ GARCÍA, M. A.: "Prohijados y "criados" en la Córdoba bajomedieval. Entre la familia y la servidumbre", en GONZÁLEZ JIMÉNEZ, M. (ed.): La Península Ibérica en la era de los descubrimientos, 1391-1492. Actas de las III Jornadas Hispano-portuguesas de la Historia Medieval, Sevilla, Junta de Andalucía-Universidad de Sevilla, 1997, p. 1280; DÍEZ, F.: Op. cit., p. 155; MARTÍN SORIANO, E.: “Aprendices y domésticos en el Alto Palancia: una estrategia familiar”, en CHACÓN JIMÉNEZ, F. y FERRER i ALÓS, L1.: Op. cit., p. 201; PEGUERO MORELL, B.: Mercaderes y artesanos en la Sevilla del descubrimiento, Sevilla, Diputación, 1986, p. 73; CARLÉ, $\mathrm{M}^{\mathrm{a}}$. del C.: "La sociedad castellana en el siglo XV: los criados", Cuadernos de Historia de España, 69, 1987, p. 110; BAIXAULI, J. y AMPARO, I.: "El treball domèstic femení a la València dels sis-censt. De Polònia Seu a la casa de mossèn Aierdi”, Studis. Revista de Historia Moderna, 30, 2004, p. 139; MARTÍN CASARES, A.: "Domestic Service in Spain", en FAUVE-CHAMOUX, A. (Ed.). Domestic Service..., Op. cit., p. 204; VAL VALDIVIESO, Ma. I.: "Mujer y trabajo en Castilla al final de la Edad Media", Aragón en la Edad Media. Homenaje a la profesora Carmen Orcástegui Gros. XIV-XV, vol. II, Zaragoza, 1999, p. 1587. 


\begin{tabular}{|c|c|}
\hline \multicolumn{2}{|c|}{ Edad de los criados salmantinos a la firma del contrato (1601-1650) } \\
\hline Edad/años & № de contratos \\
\hline 6 & $1(0,6 \%)$ \\
\hline 7 & $2(1,1 \%)$ \\
\hline 9 & $2(1,1 \%)$ \\
\hline 10 & $3(1,6 \%)$ \\
\hline 11 & $2(1,1 \%)$ \\
\hline 12 & $11(5,9 \%)$ \\
\hline 13 & $3(1,6 \%)$ \\
\hline 14 & $7(3,7 \%)$ \\
\hline 15 & $1(0,6 \%)$ \\
\hline 16 & $5(2,6 \%)$ \\
\hline 17 & $18(9,6 \%)$ \\
\hline 18 & $5(2,6 \%)$ \\
\hline 20 & $4(2,1 \%)$ \\
\hline Sin determinar. Menor de 14 & $3(1,6 \%)$ \\
\hline Sin determinar. Entre 14 y 24 & $36(19,3 \%)$ \\
\hline Sin determinar & $72(38,5 \%)$ \\
\hline Mayor de edad & $12(6,4 \%)$ \\
\hline
\end{tabular}

del dicho lugar de Arcediano..."43. A veces estas niñas recibían a cambio de su trabajo una educación en las tareas que la sociedad de entonces consideraba propias de la mujer como labrar y coser "... y aquellas cosas que mejor se inclinare...."44.

Estas entregas de niñas a familiares para criarlas y mantenerlas a cambio de su servicio, aunque éste se soslayase, podían responder a situaciones de precariedad de los progenitores. Así lo declaraban Juan Alvarado y Ana García: “... por quanto nosotros estamos pobres y tenemos hijos y no tenemos con qué poderlos criar y alimentar y enseñar labor a las hijas; siendo esto notorio a María Téllez García, nuestra hermana e cuñada, nos ha pedido le demos de más de otra hija que la tenemos dada, a Juana María, nuestra hija, que ella se encarga de tenerla recojida y de enseñarla y [a]dotrinalla aunque no tiene necesidad de ella para su serbizio y nosotros se la queremos dar...". Estaría con su tía hasta alcanzar al edad de "... tomar estado y si antes la quisiéremos sacar no havemos de ser oydos en juiçio ni fuera dél hasta que primero

43 Tomé Sánchez Ramiro, procurador del número, tomó a su sobrina para criarla por espacio de 8 años obligándose a alimentarla, vestirla, calzarla y curarla en sus enfermedades sin llevarla cosa alguna. Su mujer la enseñaría a hacer labor y no la impelería a realizar a oficios menesteriles fuera de casa. Este adiestramiento en labores, probablemente de costura, suele ser raramente mencionado. A.H.P.Sa. P.N. Leg. 3524. 11-V-1628. Fols. 1009-1010; Leg. 4376. 19-II-1638. Fols. 1105-1106; Leg. 2966. 18-XI-1612. Fols. 1868-1869.

44 A.H.P.Sa. P.N. Leg. 3502. 9-X-1613. Fols. 766-767; Leg. 2970. 18-III-1615. Fols. 772-773. 
y ante todas cosas hayamos pagado de contado a la dicha María Téllez los alimentos que hubiere dado a la dicha Juana María, nuestra hija, desde hoy día de la fecha desta escritura en adelante, a razón de dos reales por día, de comida, calzado y vestido por llevarla como la lleva para recojerla y [a]dotrinarla y enseñarla a su costa y no para servirse de ella porque para eso confesamos no la havía menester; no obstante que la dicha Juana María, nuestra hija, ha de hazer dentro de la casa de la dicha María Téllez García todo aquello que la susodicha le ordenare...”. Además, le concedieron la facultad de poder casar a ambas niñas sin el consentimiento paterno -bajo la expresión: pueda disponer de ellas como madre-45. Situaciones similares vivieron las hijas bastardas criadas por sus supuestos padres ${ }^{46}$.

Al margen de estas vivencias excepcionales, en el caso de las criadas más jóvenes sometidas a relaciones contractuales de larga duración - de hasta diez y doce años- se solía especificar que se trataba de un modo de criarlas hasta que llegasen a la edad pupilar -14 años- especialmente por los sectores más desfavorecidos como las viudas ${ }^{47}$. Catalina Gómez, viuda, vecina del lugar de la Peña, situó a su hija María Gómez, de siete años de edad con doña Antonia de Guzmán para que la criase, enseñase y adoctrinase desarrollando sus labores “... conforme a como las mozas sirben que son de su hedad..."48. La pretensión de una formación religiosa de la menor no suele aparecer en los contratos. En ocasiones cuando estas niñas llegaban a cierta edad no se conformaban simplemente con la manutención pactada ${ }^{49}$. Esta contratación de niñas de corta edad durante períodos prolongados de tiempo fue habitual en otros lugares de España

45 A.H.P.Sa. P.N. Leg. 4344. 3-XI-1621. Fols. 918-919.

46 En el principado de Asturias, en el siglo XVIII, cuando una mujer enviudaba los hijos tenían por costumbre reclamar la soldada mientras conviviesen con ella. BERTRAND BASCHWITZ, C. y DÍEZ, A.: "Mujeres solas en la ciudad del siglo XVIII", en LÓPEZ CORDÓN, Ma. V. y CARBONELL ESTELLER, M. (ed.): Op. cit., p. 167; A.H.P.Sa. P.N. Leg. 4391. 7-II-1648. Fols. 900-902.

47 A.H.P.Sa. P.N. Leg. 3517. 7-VIII-1624. Fols. 168-169.

48 A cambio percibiría simplemente la comida, vestido y calzado. Además, no la podría despedir y de hacerlo la devolvería a la localidad donde residiese la madre o en su defecto le buscaría otro servicio tan bueno como el que dejaba. María del Carmen García Herrero apunta que el adoctrinamiento además de llevar implícita la idea de formación religiosa encerraba un significado de respeto y acatamiento a los valores jerárquicos establecidos, entre ellos el honor y obediencia debida a los padres. A.H.P.Sa. P.N. Leg. 3542. 12-XI-16339. Fols. 1911; Leg. 3885. 19-VIII-1602. Fols. 390-391; GARCÍA HERRERO, Ma . del C.: Las mujeres en Zaragoza en el siglo XV, vol. I. Zaragoza, Ayuntamiento de Zaragoza, 1991, p. 117.

49 Catalina Realera se asentó con Juan Rodríguez de Villaverde, procurador del número, y habiendo estado con él dos años lo abandonó. La causa estaba en que hasta agora ha sido niña pequeña, de poco serviçio, y desde aqui adelante conbiene se le dé algo más, a cuya causa la dicha muchacha se salió de casa del susodicho. Y porque está satisfecho [el curador] de que en su casa se le haze buen tratamiento y se mira por su honra, y que la ha criado y [a]dotrinado mucho tiempo desde que sus padres murieron, y conbiene a su honor que [e]sté y sirva en su casa... se garantizó su continuidad a cambio de que se le pagase lo que se acostumbraba a las muchachas de su edad -entonces contaba con tan solo 11 años-. A.H.P.Sa. P.N. Leg. 4086. 5-V-1603. Fol. 316. 
ya desde finales de la Edad Media ${ }^{50}$. Los hogares menos favorecidos, ante la imposibilidad de mantenerlas, se veían obligados a actuaciones de tal índole ${ }^{51}$.

Parte de las jóvenes se encontraban en condiciones precarias y solían necesitar el trabajo al menos para vestirse ${ }^{52}$. A menudo se les requería la licencia del Corregidor o del Alcalde Mayor para poder entrar a servir. Por otro lado, dado que se trataba fundamentalmente de mujeres en estado célibe - dos tercios de los contratos-, se veían obligadas a buscar este tipo de empleos para no arriesgarse a caer bajo la persecución del brazo de la justicia. En 1647 el Corregidor salmantino promulgó un auto en virtud del cual ordenaba que “... todas las mugeres solteras se p[usiese]n a servir dentro de ocho días pena de seis días de cárcel, de destierro desta ziudad y su jurisdiçión por un año por la primera vez que no lo cumplieren; y la segunda, la pena doblada y de cortarles los cavellos y çejas y sacallas públicamente desterradas desta ziudad y de su jurisdiçión. Que ninguna persona reçete en su casa mugeres solteras, más de las que verdaderamente les sirvieren pena de veinte ducados para la cámara y gastos de justicia y soldados montados del Consejo, por la primera vez, y la segunda la pena doblada y que se procederá como más haya lugar de derecho....53. Este tipo de disposiciones

50 En Barcelona de los 17 contratos estudiados por P. Bonnassie, 15 de ellos se refieren a niñas de menos de 13 años. La duración de los contratos fue inversamente proporcional a la edad de las sirvientas. Situaciones similares se aprecian en Málaga, Mallorca o en Zaragoza, entre otros. LÓPEZ BELTRÁN, $M^{a}$. T.: "La accesibilidad de la mujer al mundo laboral: El servicio doméstico en Málaga a finales de la Edad Media", en LACARRA, Mª . E.: Estudios Históricos y Literarios sobre la mujer medieval, Málaga, Diputación Provincial de Málaga, 1990, pp. 119-142; BONNASSIE, P.: La organización del trabajo en Barcelona a fines del siglo XV, Barcelona, C.S.I.C, 1975, pp. 104-105; CAMPO GUTIÉRREZ, A. del: "Mozas y mozos sirvientes en la Zaragoza de la segunda mitad del siglo XIV", Aragón en la Edad Media, 19, 2006, p. 104; BARCELÓ CRESPI y FERRER VIDAL, M. A.: "El servicio doméstico femenino en la Mallorca Bajomedieval”, en RAMOS, Ma . D. y VERA, Ma. T. (eds.).: Op. cit., pp. 208-210.

51 Lo mismo le sucedió en la centuria siguiente a las instituciones que albergaban expósitas. El trabajo de las niñas estuvo en estos casos ligados a la necesidad de recuperar parcialmente el dinero invertido por sus criadores a través de su trabajo. RODRÍGUEZ GONZÁLEZ, A.: "La utilidad del abandono: las expósitas del Hospital de Santa Cruz y el servicio doméstico en Toledo en la segunda mitad del siglo XVIII", en IRIGOYEN LÓPEZ, A. y PÉREZ ORTIZ, A. (eds.): Familia, transmisión y perpetuación (siglos XVI-XIX), Murcia, Universidad de Murcia, 2002, p. 88.

52 Respecto a alguna de las contratadas se indica que entraba en el mundo del servicio por ser, como es, pobre y huérfana, por estar desnuda o tener necesidad de vestirse y calçarse y alimentarse. A.H.P.Sa. Leg. 3885. 15-VII-1602. Fols. 372-373; Leg. 4690. 18-V-1610. Fols. 1310-1311; Leg. 4698. 19IX-1617. Fols. 2364-2365; Leg. 5478. 13-XI-1623. Fol. 674; Leg. 4008. 19-XI-1626. Fols. 439-442; Leg. 3899. 3-VI-1633. Fols. 950-951.

53 En Sevilla, por el contrario, los jurados de la ciudad para obviar los abusos cometidos en el alquiler de las mujeres de servicio requirieron que fuesen casadas y de buena opinión. A.H.P.Sa. P.N. Leg4025. 4-IV-1647; BERNAL, M., COLLANTES DE TERÁN, A. y GARCÍA-BAQUERO, A.: "Sevilla: de los gremios a la industrialización”, Estudios de Historia Social, 5, 1978, p. 137. 
respecto a las mozas de servicio fueron usuales en otras ciudades españolas y extranjeras; tenían por objeto evitar un exceso de población ociosa y desocupada ${ }^{54}$.

Las muchachas habitualmente iniciaban sus labores el mismo día de la redacción de la escritura, raramente hubo lo que podríamos considerar un período probatorio ${ }^{55}$. En los casos conservados y para períodos de contrato de un año, el tiempo de prueba solía ser inferior a un $\mathrm{mes}^{56}$. Entre los ejemplos se halla el de Constanza Espinera quien se puso a servir con el impresor de libros Jerónimo Villalonga por un año: “... estando un mes a contento de anvas partes, porque contentos prosiga su año adelante que corra desde hoy día de la fecha..."

La duración del contrato extraordinariamente sobrepasaba los cuatro años siendo un año la cifra modal. Solamente hemos hallado uno por un período indefinido, el de Pedro Sánchez, el Mozo, quien se puso a servir al convento de San Antonio de Paula de la Orden de Mínimos de Salamanca "por todo el tiempo de su vida"58. Mientras él lo desease no le podrían echar “... si no fuera con causa lijítima que este convento tenga, como es por incorrejible y dar mal exenplo y hazer algo menos [hurtar] a esta dicha casa y ser deshonesto...". Además de mantenerle y vestirle le atenderían en todas sus enfermedades "sin que pudiere pedir otra cosa alguna". Se sobreentiende que no cobraría nada en metálico ${ }^{59}$. El período convenido podía acortarse en función de un pacto previo ${ }^{60}$.

54 VILLALBA PÉREZ, E.: "Posibilidades femeninas de vida individual en la España de los Austrias", en LÓPEZ CORDÓN, Ma. V. y CARBONELL ESTELLER, M. (ed.): Historia de la mujer e historia del matrimonio. Historia de la Familia. Una nueva perspectiva sobre la sociedad europea, Murcia Universidad de Murcia, 1997, p. 117; BRUNELLE, G. K.: Op.cit., p. 390.

55 Inés Paces se comprometió con Diego de Calamón, zapatero, al mes siguiente de la firma. En Japón durante el siglo XVII existió un período de prueba de 5 días para los criados y se les exigía, además, un fiador capacitado. A.H.P.Sa. P.N. Leg. 5472. 3-XII-1618. Fols. 825-826; NAGATA, Ma . L.: "Domestic Service and the Law in Early Modern Japan", en FAUVE-CHAMOUX, A. (ed.): Domestic Service..., Op. cit., pp. 213-214.

56 A.H.P.Sa. Leg. 5476. 29-V-1621. Fols. 628-629.

57 En el caso de Catalina Pérez, criada del procurador Lorenzo Hernández, se especificaba que si al cabo del mes no se contentare cualquiera de las partes la iguala ser[í]a en sí ninguna. A.H.P.Sa. P.N. Leg. 3503. 25-VI-1614. Fol. 930; Leg. 5706. 22-VII-1615. Fol. 668.

58 En otros lugares los contratos de mayor duración llegaron a cifras similares a las salmantinas. En Martos, por ejemplo, a los 11 años. En ciudades como Valladolid estaba regulado que las mozas sirviesen a sus amos un mínimo de seis meses y se efectuase el acuerdo por escrito pena de cien azotes y cuatro años de destierro. LÓPEZ MOLINA, M.: "La mujer en Martos en la segunda mitad del siglo XVI", en VV.AA.: Actas del II Congreso de Historia de Andalucía, Tomo III, Córdoba, Junta de Andalucía, 1991, p. 254; AGUADO, A. M. et alii: Textos para la historia de las mujeres en España, Madrid, Cátedra, 1994, p. 270.

59 A.H.P.Sa. P.N. Leg. 4244. 21-X-1601. Fols. 36-37.

60 Inés Martínez concertó con Juan Sánchez que estaría en su casa un año pero si antes de cumplirlo venían de su tierra a recogerla para llevársela no la podría obligar a servir por más tiempo yéndose fuera de la ciudad. A.H.P.Sa. P.N. Leg 5781. 21-V-1615. Fol. 59. 


\begin{tabular}{|c|c|}
\hline Duración del contrato/ años & Número de contratos \\
\hline Sin determinar & $25(13,4 \%)$ \\
\hline Menos de 1 año & $2(1 \%)$ \\
\hline 1 & $88(47 \%)$ \\
\hline Entre 1 y 2 & $4(2,1 \%)$ \\
\hline 2 & $29(15,5 \%)$ \\
\hline 3 & $11(5,9 \%)$ \\
\hline 4 & $11(5,9 \%)$ \\
\hline 5 & $2(1 \%)$ \\
\hline 6 & $5(2,7 \%)$ \\
\hline 7 & $1(0,6 \%)$ \\
\hline 8 & $4(2,1 \%)$ \\
\hline 10 & $3(1,6 \%)$ \\
\hline 12 & $1(0,6 \%)$ \\
\hline Indefinido & $1(0,6 \%)$ \\
\hline
\end{tabular}

\section{b) El salario del servicio doméstico.}

La mayoría las jóvenes realizaban su trabajo fundamentalmente a cambio de la manutención, ropa limpia, cama ${ }^{61}$, calzado y sobre todo el vestido -de este modo se especifica en la mitad de los casos- ${ }^{62}$. Proveer de la comida a las sirvientas era obligatorio. Así lo expresaba Isabel Méndez, en un pleito contra su tío, el clérigo Francisco de Silva, quien alegaba que éste aunque la había dado de comer no por ello le quedaba de pagar "... el salario conforme a derecho pues todas las criadas, demás de la comida, ganan el salario..." 63 . El vestido entregado anualmente constaba habitualmente de dos camisas - de lienzo casero o de estopa-64; dos cofias, mandiles, calzas -de frisa, coloradas y de lana basta- ${ }^{65}$; saya- de palmilla o de paño fraileñ ${ }^{66}{ }_{-}$, y sayuelo

61 No todos los criados dormían en casa de sus amos, especialmente los casados, aunque también algún soltero mantuvo cierta independencia. María Hernández, declaraba en su testamento estar viviendo en un aposento de un tal Estacio Tercero a quien pagaba de renta un ducado por año. A.H.P.Sa. P.N. Leg. 3892. 6-VI-1622. Fols. 254-255.

62 Este vestido podía tener un precio elevado. Juan Martín de Valencia, paje de don Gaspar Rodríguez de Labanda y Monroy, recibió uno de paño acanalado de mezcla que ascendió a 205 reales. Su sueldo era 168 reales anuales, además de 16 maravedíes y dos libras diarias de ración. A.H.P.Sa. P.N. Leg. 3274. 2-IX-1631. Fols. 563-564.

63 A.H.D.Sa. Leg. 6-27. 5-V-1605.

64 En ocasiones se indica: altas con cabezón labrado, el cuerpo de sedija y el ruedo de estopa altas; de lienzo los cuerpos y los ruedos de estopa cruda; de cuello alto que tengan lechuguilla o de la que se acostumbra a dar a las mozas de servicio A.H.P.Sa. P.N. Leg. 5472. 5-XII-1618. Fols. 803-804; Leg. 3681. 10-XI-1627. Fols. 491-492; Leg. 5891. 17-V-1642. Fol. 1371; Leg. 4686. 2-IX-1607. Fols. 1191-1192; Leg. 3672. 5-IX-1605. Fols. 429-430; Leg. 3505. 6-V-1614. Fol. 928; Leg. 3520. 18-IX-1626. Fol. 1142.

65 A.H.P.Sa. P.N. Leg. 5488. 4-V-1629. Fols. 971-972.

66 A.H.P.Sa. P.N. Leg. 4256. 28-X-1639. Fol. 94. 
-de color verde o azul- de paño de palmilla- ${ }^{67}$. En menor medida les proporcionaban ligas, mantellinas o mantellines -de frisa-, greguescos, faldas, ferreruelos, ropillas -de paño pardo-, medias calzas, calzones, capote o capotillo - de dos aldas- pretina, manteo -de sayal-68, basquina, tocas, gorgueras, jubón -de camuza guarnecido-, servilletas, montera de paño ordinario, ropilla, valón, faja para cobijar, sombreros y cuerpos de lienzo ${ }^{69}$. En ocasiones se estipulaba que el paño de estos vestidos fuese común, “... del ordinario y que se suele dar a las mozas de soldada de la ciudad..."70; en otras "de mediano preçio, lo mexor que pudieren"71. En algún documento se dejó a elección del amo el que alguna de las prendas pudiese ser de segunda mano, mientras que en otros se exigía que fuese todo nuevo ${ }^{72}$. También a veces se daba a la criada la posibilidad de poder elegir su salario mediante un vestido o en metálico ${ }^{73}$. En el caso del calzado se le proporcionaba todo el que pudiera romper. Excepcionalmente y para niñas que firmaron acuerdos de larga duración - de diez años- se podían entregar objetos que entrarían a formar parte del ajuar de la moza. Antonia Martín, al servicio

67 Podía dársele al final un vestido completo de paño nuevo que incluyese unos cuerpos, saya y camisa. El precio del mismo oscilaba entre 7 y 10 reales la vara. En algún contrato se indica que el vestido fuese el primer año de color azul, el segundo verde y el tercero a elegir por la menor. Probablemente, el azul y el verde constituyeron los dos colores asociados al mundo del servicio. En los testamentos aparecen legados de las criadas a sus compañeras de trabajo de los manteos de color azul que traían habitualmente. A.H.P.Sa. P.N. Leg. 3229. 4-V-1601. Fol. 58; Leg. 5089. 21-VIII-1602. Fols. 496-497; Leg. 4340. 23X-1618. Fols. 701-702; Leg. 5569. 8-VIII-1607. Fols. 900-901; Leg. 5571. 14-III-1609. Fols. 702-703; Leg. 4882. 21-XII-1611. Fols. 754-756; Leg. 4883. 3-VI-1613. Fols. 844-845; Leg. 4252. 17-II-1625. Testamento de Isabel de Figueroa, moza de servicio. Fols. 381-382.

68 A.H.P.Sa. P.N. Leg. 4362. 28-IX-1630. Fols. 277-278.

69 La entrega del vestido y calzado puede aparecer bajo expresiones genéricas como desde el pie hasta la cabeza de forma que and[uvies]e bestida honestamente. En otros casos se explicita de manera más amplia. Así por ejemplo, a María Rodríguez, natural de Santiago de la Requejada, se le pagaría las hechuras que se acostunbran a dar en esta ziudad a semejantes mozas ques dos camisas de lienço y estopa y una basquiña y jubón de mezcla de la color que la dicha moza pidiere, de hasta nueve reales la vara, hecho y derecho, dos felgueras de red con sus valonas y dos garbines y todo el calçado que pudiere ronper, esto en cada un año; e ansimismo se le ha de dar una mantellina o mantilla para andar cobixada el tiempo que estubiere en servicio del dicho Juan Crespo. A.H.P.Sa. P.N. Leg. 4877. 3-IX-1602. Fols. 747-748; Leg. 4877. 21-IX-1602. Fols. 751-752; Leg. 7963. 18-V-1604; Leg. 3999. 10-I-1606. Fols. 502-503; Leg. 4358. 2-I-1628. Fol. 115; Leg. 3553. 5-VI-1648. Fol. 2078, Leg. 3674. 10-IX-1607. Fol. 416; Leg. 5569. 8-VIII-1607. Fols. 900-901; Leg. 3498. 13-X-1610. Contrato de María Rodríguez. Fols. 205-206; Leg. 4339. 27-IX-1617. Fol. 565; Leg. 4888. 7-VI-1623. Fols. 1274-1275; Leg. 4112. 15-VII-1636. Fol. 759.

70 Otras veces se exige paño pardo de la ciudad, de Piedrahita, del Barco o bejarano. A.H.P.Sa. Leg. 4086. 22-X-1603. Fols. 411-412; Leg. 4111. 5-VII-1629. Fols. 19-20.

71 A.H.P.SA. Leg. 3891. 4-IX-1617. Fols. 365-366.

72 En el de María Díez se especificaba que la mantellina fuese de lo que vos [el amo] le quisieres dar, nueva o vieja. María Sánchez, recibiría de sus amos Pedro de Miranda y Catalina Chamosa, algún vestido como ande moderadamente, biejo o nuevo, el que los susodichos le quisiéredes dar A.H.P.Sa. P.N. Leg. 3492. 4-I-1604. Fols. 669-670; Leg. 5316. 11-IV-1605. Fols. 846-847; Leg. 5570. 24-XI-1608. Fol. 806.

73 A María Rodríguez se le ofreció la posibilidad de percibir 7 ducados en dinero o en vestidos, qual más ella quisiere. A.H.P.Sa. P.N. Leg. 4245. 13-X-1606. Fol. 240. 
de José Sanz, procurador del número de Salamanca, recibiría al final de su servicio “... una cama de ropa con madera de cordeles que se entiende xergón, colchón, dos sábanas, dos mantas y dos almohadas, todo bueno..."74.

El salario podía ir parcialmente destinado a los padres. En los memoriales de los amos aparecen a veces pagos en especie a los progenitores de los mozos. Catalina de San Juan, viuda, declaraba en el suyo lo siguiente: “... Y ansimesmo, ha que me sirve María Carrera, la pequeña, para San Juan cumple çinco años. Téngole dados dos sayas y dos sayuelos y tres mandiles y cada año dos camisas. Sólo el que corre no se las tengo dadas. Demás desto le tengo [entregado] a su madre veinticuatro reales en toçino. Lo demás le devo y esto se entiende en paño hurdinario..." 75 .

No hemos encontrado casos en Salamanca, a diferencia de Granada, donde los servicios realizados por los menores respondiesen al pago de deudas o préstamos recibidos por los padres $^{76}$.

Cuando la remuneración tenía un carácter monetario solía ser inferior a los 100 reales anuales. No todos percibieron, además del mantenimiento, una cantidad en dinero -al menos cuatro de cada diez criados de los citados contratos-. Parte del salario podía adelantarse con el objeto de que las jóvenes adquiriesen algún tipo de vestido ${ }^{77}$. En muchos casos se suele indicar que éste se le iría proporcionando a medida que lo necesitasen-lo hubieren menester- o lo fuesen pidiendo y ganando, de forma que las muchachas anduviesen bien tratadas ${ }^{78}$. No es frecuente concertar pagos fraccionados a lo largo del año ${ }^{79}$. Como ya hemos señalado se observan sistemas mixtos con remuneraciones tanto en vestidos como dinero ${ }^{80}$; o en prendas los primeros años y en metálico los siguientes, con incrementos en el salario a medida que aumentaban los años de servicio ${ }^{81}$.

74 A.H.P.Sa.P.N. Leg. 4358. 2-I-1628. Fol. 115.

75 A.H.P.Sa. P.N. Leg. 5375. Año 1629. Fol. 293 r.

76 MORENO TRUJILLO, Ma . A et alii: "El contrato de trabajo en la Granada del siglo XVI: el campo, la casa y la ciudad", Cuadernos de Estudios Medievales y Ciencias y Técnicas Historiográficas, 17, 1992, p. 245.

77 A.H.P.Sa. P.N. Leg. 3397. 7-XII-1601. Fols. 233-234.

78 En el asiento de María González se daba licencia a su ama para que gastase libremente el dinero de la soldada de la moza en los vestidos y necesidades de ésta. A.H.P.Sa. P.N. Leg. 3891. 26-X1619. Fol. 762; Leg. 5375. 11-XII-1629. Fols. 269-270.

79 A.H.P.Sa. P.N. Leg. 5482. 8-I-1625-. Fols. 616-617.

80 A.H.P.Sa. P.N. Leg.- 4683. 24-II-1603. Fols. 13-16.

81 María Hernández, asentada por espacio de cuatro años con doña Ana de Ledesma, durante los dos primeros percibiría un sayuelo de paño nuevo -de 8 reales la vara-, dos camisas y el calzado que necesitase. El tercer año 5 ducados y el cuarto año 6 ducados para vestirse o para lo que la moza hubiere menester: María Casada, en servicio del procurador del número Gabriel Álvarez, recibiría el primer año un vestido de paño y calzado; el segundo lo mismo y un ducado más. A.H.P.Sa. P.N. 4321. 18-II-1602. Fols. 794-795, Leg. 3891. 9-IX-1619. Fol. 763; Leg. 3676. 16-XI-1612. Fols. 941-942; Leg. 4890. 12-VII-1627. Fols. 893-894. 
De los adelantos y abonos de la soldada podía quedar constancia bien a través de una carta de pago o de un asiento en el libro de razón que solía poseer el amo a quien se le debía creer con su juramento, sin incoarle pleito alguno ${ }^{82}$. Los criados que trabajaban para instituciones religiosas y colegios recibían a menudo salarios más elevados que los situados al servicio de particulares ${ }^{83}$. La impresión que se percibe de los contratos es que no había homogeneidad a la hora de fijar los sueldos y en un número reducido de casos éstos quedaban a la libre voluntad de los amos aunque debían mantener una equiparación a la edad de la joven ${ }^{84}$. Así se percibe en contrato de Francisco Pérez, asentado como mozo y criado de don Pedro Fernández de Baeza, estudiante de la Universidad salmantina, natural de Méjico, con la condición de acompañarle incluso a este país si lo deseaba, durante el tiempo que el amo quisiese y con un salario a su libre albedrío aunque éste "... se entienda conforme a la hedad que tubiese el susodicho..."

Carecemos de información sobre la puntualidad en los pagos por parte de los amos en los casos de los contratos de los protocolos notariales. Solamente se conserva alguna referencia aislada a que el dinero -reales- a percibir por la criada se harían "buenos, ciertos y verdaderos"; o que serían pagados llanamente y sin pleito alguno ${ }^{86}$. Lo mismo sucede con ciertas cartas de pago mediante las cuales las sirvientas mani-

82 Como un ejemplo de constatación a través de un memorial sirva el de Catalina de San Juan, viuda: La moça questá conmigo al presente, que se llama María Galana, cumple para hebrero de seiscientos y treinta, ocho años que ha que me sirve a raçón de siete ducados y dos camisas hordinarias y le tengo pagadas todas las camisas hasta fin de año con una que tiene en casa de la costurera y lo demás que pareçiere por asiento de un livro en questá asentado; y más le devo dos camisas deste año. $Y$ demás del asiento del livro le tengo dado para un mandil ocho reales y más doçe reales que le di para sus necesidades para quando estuvo mala y más lo que pareçiere deverse al voticario. A.H.P.Sa. P.N. Leg. 5089. 16-VI-1603. Fols. 723-724; Leg. 4321. 18-II-1602. Fols. 794-795; Leg. 3492. 14-II-1604. Fols. 684685; Leg. 5375. Memorial de Catalina de San Juan, 1629. Fol. 293 r.; Leg. 4716. 31-I-1652. Carta de pago de Isabel de la Cruz, criada del licenciado Francisco Rodríguez. Fols. 335-336.

83 Juan Fernández, criado del convento de San Esteban, cobraba 220 reales anuales. María Rodríguez, lavandera y casera del Colegio Mayor de San Bartolomé, percibía 300 reales y 36 fanegas de trigo anuales. Mucho menos María Hernández, lavandera del Colegio de Niños Huérfanos, cuyo salario ascendía a 159,5 reales anuales y una fanega de trigo. A.H.P.Sa. P.N. Leg. 3742. 4-X-1605. Fols. 270-271; Leg. 2998. Testamento de María Rodríguez. 1648. Fols. 973-980; Leg. 5287. 8-X-1619. Fols. 335-336.

84 También se establecieron acuerdos mediante los cuales el individuo recibía su remuneración diariamente. Bartolomé García Vecilla, criado del maestrescuela salmantino, la tenía fijada en 3 reales diarios. A.H.P.Sa. P.N. Leg. 2998. Testamento de Bartolomé García. 7-XI-1648. Fols. 1055-1056.

85 Las cláusulas relativas a los desplazamientos de los criados no son habituales. Además de este contrato citado encontramos una única alusión en el de María de la Cruz, una niña huérfana de 12 años de edad, que se asentó por doce años con Luis Fernández para servir dentro y fuera de casa, hora residiendo en esta dicha çiudad de Salamanca con vuestra casa y familia como en otra qualquier parte donde estubiéredes y residiéredes. A.H.P.Sa. P.N. Leg. 3861. 23-IX-1627. Fols. 463-464; Leg. 4096. 8-I1613. Fols. 513-514.

86 A.H.P.Sa. P.N. Leg. 4682. 13-IX-1602. Fols. 1559-1560; Leg. 4245. 26-V-1608. Fols. 884-885. 
festaron haber percibido la totalidad de su soldada ${ }^{87}$. Testamentos, procesos judiciales, licencias matrimoniales y cartas de apartamiento nos permiten acercar a este tipo de aspectos aunque con informaciones dispares ${ }^{88}$. Las últimas voluntades de las criadas plasman que no siempre sus salarios se abonaron a tiempo. Un 35 por ciento de ellos reflejó lo que los amos quedaron debiéndoles ${ }^{89}$; un 15 por cierto indicó que se le había pagado con puntualidad y un 50 por ciento no hace referencia alguna al respecto, tal vez porque no hubiera atrasos en las soldadas ${ }^{90}$. Sólo en casos excepcionales los señores dejaron a sus sirvientes como herederos para compensarles en este sentido. Así sucedió con María Robles, criada del licenciado Nicolás Manjares, clérigo, a quien se le adeudaban 25 años de salario y 200 ducados que le había prestado ${ }^{91}$.

Apenas se conservan procesos relacionados con los impagos de las soldadas -hemos localizado tan sólo dos en el Archivo Histórico Diocesano tras el vaciado completo de los fondos-, probablemente porque en muchos de los casos las costas judiciales sobrepasasen la cuantía de la deuda contraída no resultando rentable pleitear o porque esperaban cobrarlos mediante algún legado testamentario del amo. Hemos de tener en cuenta que los salarios de las criadas no eran muy elevados y la denuncia

87 A.H.P.Sa. P.N. Leg. 5705. 15-IX-1614. Carta de pago de María García, criada de Alonso Sánchez, carpintero y María Buena, panadera, su mujer. Fol. 497.

88 Isabel Beceiro subraya cómo en la Edad Media los agravios más frecuentes de los criados se refirieron a la duración de su jornada laboral y al impago de sus salarios. BECEIRO PITA, I.: "Criados, oficiales y clientelas señoriales en Castilla (siglos XI-XIV)", Cuadernos de Historia de España, 75, 19981999 , p. 75.

89 P. Saavedra apunta que en Galicia en el siglo XVIII las soldadas convenidas no se pagaban muchas veces y los criados debían esperar a que se cumpliesen las mandas testamentarias. Los testimonios literarios manifiestan asimismo cómo los testamentos actuaron a modo de liquidación de cuentas entre amos-criados. Así se aprecia en El Quijote: “Tornóle a referir el recado y embajada que había de llevar de su parte a su señora Dulcinea, y que en lo que tocaba a la paga de sus servicios no tuviese pena, porque él había dejado hecho su testamento antes que saliera de su lugar donde se hallaría gratificado de todo lo tocante a su salario, rata por cantidad, del tiempo que hubiese servido". CERVANTES SAAVEDRA, M. de: Don Quijote de la Mancha, Madrid, Espasa Calpe, 1979, p. 110; SAAVEDRA, P.: Op. cit., p. 248.

90 Entre los múltiples casos encontramos el de María de Vibriesca, criada de don Juan Rodríguez Villafuerte Maldonado, quien alegaba que tras 20 años de servicio sólo había percibido 20.000 maravedíes. Suplicaba a sus señores le abonasen el resto para el cumplimiento de su testamento; o el de Isabel de Fuentes, quien, tras 19 años de trabajo con don Pedro de Zúñiga Palomeque, había recibido 2.034,5 reales de los 3.353 que le correspondían. En ocasiones también se demandaban los préstamos efectuados a los señores. María Pérez, además del salario, reclamó otros 300 reales que había dejado a su amo para poder sufragar los gastos de su entierro. A.H.P.Sa. P.N. Leg. 4320. 2-IX-1602. Fols. 735-738; Leg. 4087. 29-II1604. Fols. 475-478.

91 Este fenómeno se observa en otras ciudades durante la centuria siguiente aunque no tanto por atrasos salariales como por recompensar un largo y complaciente servicio. En la urbe burgalesa los eclesiásticos y militares eran los únicos que dejaron a amas o criadas como herederas. En el caso de los clérigos el 80 por ciento las legó una cama completa. A.H.P.Sa. P.N. Leg. 5709. 30-VII-1629. Fols. 11881189; LÓPEZ IGLESIAS, F. El grupo doméstico en la Asturias del siglo XVIII, Oviedo, Real Instituto de Asturianos, 1999, p. 146; SANZ DE LA HIGUERA, F. J.: "En casa, [cama] y compañía. Yacer a lomos del siglo XVIII en los hogares eclesiásticos burgaleses", Hispania Sacra, vol. LVIII, 118, 2006, pp. 568-569. 
al señor podía acarrear algunos riesgos. Catalina Rodríguez, demandó ante el tribunal eclesiástico a su antiguo amo Gonzalo Moreno, arcipreste de Calzada de Valdunciel, por un impago de 15 ducados por 15 meses de trabajo. Éste, a su vez, la acusó, de haberle llevado hacienda de su casa ${ }^{92}$. Las escasas leyes que regularon el cobro de los salarios se centraron en fijar plazos - de tres años- para reclamarlos tras haber sido despedidos por sus señores. Respondían, según una petición de las Cortes, a un deseo de acabar con los pleitos ocasionados al respecto por las reclamaciones efectuadas a los herederos de los amos y a la dificultad de probar todo lo percibido por los sirvientes ya que eran “... cosas que se paga[ba]n por menudo y en diversos tiempos..."

Sólo en un número reducido de casos, estas situaciones de falta de pago llevaron al encarcelamiento de los deudores, tal como sucedió a Andrés Nieto, mayordomo de Antonio del Castillo, regidor salmantino, por una deuda de 330 reales con dos criados $^{94}$. No son tampoco abundantes las escrituras de transacción y concordia entre partes ante los escribanos para solucionar este tipo de desavenencias laborales por las soldadas ${ }^{95}$. Excepcionalmente, las criadas acababan perdonando las deudas de sus señores al final de sus días por la mucha voluntad y afición que les habían tenido, o simplemente por hacer [les] gracia de ello ${ }^{96}$. Este tipo de actuaciones solía estar ligado a mujeres que no tenían grandes necesidades económicas -fue el caso de María Hernández quien gozaba de una renta anual de 4 ducados legada por su tío- y que habitualmente dejaban a su alma por heredera.

En ocasiones las criadas confiaban en sus amos el pago de los atrasos sin expresar la cantidad adeudada por su soldada ${ }^{97}$. En los testamentos aparecen expresiones como “... lo que él dijere sin que nadie le pueda pedir más cuenta de la que quisiere dar ... por la mucha satisfacción que he tenido del dicho mi amo; lo que dijere el dicho mi señor simplemente haberme dado se le tome en qüenta y rebaje de lo que ansí me debe

92 Este tipo de proceder se dio también en Galicia. Allí cuando los criados denunciaban impagos de servicios a sus amos podían a su vez ser acusados de haber hecho desaparecer algunos granos o de amancebamiento. A.H.D.Sa. Leg. 8-18. Año 1607; DUBERT, I.: Op. cit., p. 294.

93 CORTES DE CASTILLA Y LEÓN, Tomo IV, Cortes de Madrid de 1528, p. 520; Recopilación de Leyes...: Op. cit., Lib. IV. Tit. XV, Ley IX y Lib. VI. Tit. XX. Ley. I, fol. 198.

94 Se le soltó a cambio de un pago de 8 ducados. A.H.P.Sa. P.N. Leg. 4968. 6-II-1604. Fol. 1455; Leg. 2982. 26-XII-1628. Fols. 843-844.

95 A.H.P.Sa. P.N. Leg. 4692. 4-IV-1612. Fols. 1707-1709; Leg. 5782. 23-IX-1621; Leg. 4734. 4-IV-1650. Fols. 872-873.

96 No sucedía lo mismo con los préstamos impagados que habían efectuado los criados a sus amos. Juan de Grado, al servicio primero de don Lorenzo de Medina y después de su yerno don Antonio Maldonado de Tejeda, durante más de 40 años, reclamó 100 ducados que había dejado a la mujer de éste último pero perdonó lo que se le debiese de salario. A.H.P.Sa. P.N. Leg. 4683. 24-II-1603. Fols. 13-16; Leg. 3529. 25-VI-1631. Fols. 1556-1557.

97 A.H.P.Sa. P.N. Leg. 3888. 30-VI-1607. Fols. 257-258. 
y se esté a su sinple declaraçión ... por la satisfaçión que tengo de su persona y cristiandad..."98; o se remiten a los libros de asiento del amo ante quien manifiestan esa "entera satisfacción” ya que en él tenía “... puestos justificadamente toda razón y verdad como hombre ques de consziencia y de quien más que eso fío..."

Otros esperaban a cambio una actuación de sus señores en favor de sus almas, probablemente sufragando parte del funeral o algunas misas. Jerónimo de Villacreces, en servicio de don Diego Antonio de Anaya y Chaves, insertaba en su última voluntad la siguiente disposición: “... Yten, declaro que de todo el tiempo que he serbido a los dichos señores tengo hecha qüenta con mi señor don Diego Antonio de Anaya; mando no se le pida qüenta ni razón dello más de la que sus merzedes quisieren dar, que yo fío me harán merced y limosna en acordarse de mi alma y en caso nezesario le doy carta de pago de mis salarios..."100.

Los testamentos también podían actuar de plataforma no sólo para expresar que estaban al día de sus salarios, sino también de agradecimiento a los amos. Isabel de Villanueva, criada de Francisco Prado afirmaba lo siguiente: “...Yten, declaro que todo el tiempo que he servido a los dichos mis señores me le han pagado hasta el día de hoy e no me deben nada, antes yo les soy deudora de muchas y mui buenas obras que de sus merçedes he recibido..."101.

Al margen del peculio, las cláusulas contractuales podían exigir la asistencia médica del criado en tiempo de enfermedad cubriendo los gastos de médico, barbero y botica ${ }^{102}$. Se trata de una prerrogativa limitada a un número reducido de casos, tan solamente siete de los contratos lo expresan -un 3,7 por ciento de los mismos-. Además, traspasado cierto límite temporal podía quedar a la voluntad del amo la prorrogación de la asistencia médica o la decisión de mandar a la joven al hospital ${ }^{103}$.

98 A.H.P.Sa. P.N.Leg. 2991. 6-XII-1639. Testamento de Martín Blas, criado. Fols. 860-861; Leg. 4729. Año 1645. Fols. 5-6; Leg. 4724. 25-I-1640. Fols. 55-56.

99 A.H.P.Sa. P.N. Leg. 5710. 28-XI-1631. Fols. 1294-1297.

100 De manera similar se expresaba Catalina Rodríguez: ... que del dicho tiempo quiero no se le tome qüenta, que ella [el ama] es tan buena christiana que si alguna cosa me debiere lo pagará, que estoi cierta no me debe cosa alguna, que siempre me lo iba pagando y me ha curado en mis enfermedades, $y$ ésta de que estoi enferma que ha muchos dias, y en todas me ha regalado. A.H.P.Sa. P.N. Leg. 4356. 17III-1627. Fols. 709-710; Leg. 3769. 7-VII-1630. Fol. 528.

101 A.H.P.Sa. P.N. Leg. 3524. 11-XII-1628. Fols. 237-238

102 A.H.P.Sa. P.N. Leg. 5274. Fols. 1004-1005; Leg. 4358. 2-I-1628. Fol.115.

103 Así aparece en el contrato de María de Salamanca con María Flórez, su tía, quien se comprometió a curarla como no pas[as]e de un mes porque cumplido, sea a escoger de la dicha María Flórez curarla e no. En el de María Carretón se disponía que en el supuesto de estar mala permanecería ocho días en casa del ama hasta ver si mejoraba; en caso contrario se la trasladaría a un hospital para curarse y tras la mejora recuperaría el tiempo perdido. A.H.P.Sa. P.N. Leg. 3397. 7-XII-1601. Fols. 233234; Leg. 4877. 3-IX-1602. Fols. 747-748. 


\section{c) Tareas y compromisos contractuales.}

El servicio, al menos en los contratos por escrito, se desarrolló con una dedicación exclusiva a un único amo aunque sólo dos de los documentos lo indiquen de manera específica, bajo fórmulas como que no podría "servir a otro nadie o a otra persona"104. Las faenas a realizar raramente eran especificadas en los documentos. En ocasiones aparecen mencionadas de una manera genérica: "que sean honestas y pusibles de hacer"105; trabajarían “... en todo lo que le mandaren servir; en todo lo que le quisiere mandar sin poner excusa o dilación alguna..." "106; “... en todo lo que fuere menester y lícito..."107; “... en los oficios menesterosos de casa, lícitos y honestos..."108; “ “.. en todo lo necesario, justo y conveniente...”109; “... conforme a otras mozas de soldada sirven o lo demás que acostumbran a hazer las mozas de serbizio..." ${ }^{110}$. A través de estas expresiones se aprecia cómo la licitud y la conveniencia fueron las únicas cortapisas para unos amos que podían actuar prácticamente a su antojo. Algunas escrituras sí establecieron una diferenciación entre labores "de casa y fuera" de ella11. Entre las primeras se encontraba barrer, hacer las camas, fregar, limpiar candeleros o guisar. Entre las segundas ir al río -probablemente a lavar ropa o a por agua- y al horno - a cocer pan-, tal y como se desprende de las declaraciones del

104 No obstante, encontramos casos aislados de criados que durante el verano se dedicaban también a ganar dinero en labores agrarias. María Hernández, portuguesa, en servicio de Antonio Nieto, cerero, afirmaba en su testamento que había ido a segar el año anterior y ganó 16 ducados que entregó a su señora con los cuales quería se sufragase su entierro. A.H.P.Sa. P.N. Leg. 4331. 9-VII-1609. Fols. 862-863; Leg. 5714. 6-V-1643. Fols.150-151; Leg. 5474. 7-IX-1620. Fols. 1057-1058.

105 A.H.P.Sa. P.N. Leg. 5089. 18-V-1601. Fols. 316-317.

106 A.H.P.Sa. P.N. Leg. 3397. 7-XII-1601. Fols. 233-234; Leg. 3746. 17-XI-1608. Fols. 526.

107 A.H.P.Sa. P.N. Leg. 4877. 21-X-1602. Fols. 754-55; Leg. 4878. 20-X-1604. Fol. 1065.

108 A.H.P.Sa. P.N. Leg. 3517. 7-VIII-1624. Fols. 168-169.

109 A.H.P.Sa. P.N. Leg. 5468. 11-VIII-1611. S.f.

110 Similar a ésta: de todo lo nezesario en la forma y manera que las moças y criadas de soldada sirben a sus amos. A.H.P.Sa. P.N. Leg. 3673. 15-II-1606. Fols. 291-292; Leg. 4372. 2-XI-1635. Fols. $202-$ 203; Leg. 3546. 31-VIII-1643. Fol. 1265.

111 La mayoría de los contratos establecía que realizasen todas las labores lícitas en ambos ámbitos -dentro y fuera-. Sólo excepcionalmente se firmaban en uno u otro sentido. Francisca González entró al servicio de Juan de Mendoza, alguacil de corte, de donçella de dentro de casa y si saliere fuera -acompañando a la mujer del alguacil o a servir- ha de ser con su manto y hávito deçente. Además de esta distinción, entre los criados de la aristocracia había categorías como mayores - "de escaleras arriba"- y menores - "de escaleras abajo o de librea", o asalariados y no asalariados - a recompensa-. A.H.P.Sa. P.N. Leg. 4879. 29-I-1605. Fol. 428; Leg. 5584. 2-X-1628. Fols. 244-245; Leg. 3497. 31-IX-1609. Escritura de asiento de María del Castillo. Fols. 138-139; Leg. 4698. 19-IX-1617. Fols. 2364-2365; Leg. 5471. 7-VIII1617. Fols. 722-723; Leg. 5488. 13-II-1629. Fol. 911; Leg. 2983. 25-II-1630. Fols. 866-867; ARAGÓN MATEOS, S.: "Amos y criados en la Extremadura dieciochesca", en Actas del Congreso Internacional sobre Carlos III y la Ilustración”, tomo II, Economía y Sociedad, Madrid, Ministerio de Cultura, 1987, p. 408; CARRASCO MARTÍNEZ, A.: "El servicio doméstico femenino de la aristocracia en el Antiguo Régimen”, en RAMOS, Mª D. y VERA, Ma. T. (eds.): Op. cit., p. 272. 
proceso de Isabel Méndez, criada y sobrina del clérigo Francisco de Silva ${ }^{112}$. Tampoco se indica nada sobre la duración de la jornada laboral. Carmen Sarasúa indica, al menos para el siglo XVIII, que dependía de las necesidades y gustos de la familia y podía llegar a las 16 horas diarias. La subordinación a los amos, incluso durante la noche, convertía el servicio en un trabajo "que nunca acababa"113.

Las mozas de soldada se comprometían a servir fielmente y a no ausentarse de la casa durante el período acordado. En ocasiones se les exigía incluso un fiador para garantizarlo y evitar posibles sustracciones ${ }^{114}$. En su defecto, había otras formas de lograr su continuidad. Así por ejemplo, se relegaba la totalidad del pago de la soldada hasta la finalización del tiempo estipulado y en caso de marcharse no percibirían nada ${ }^{115}$. También podían castigarlas con el doble de las costas y menoscabos que ocasionasen a su señor o deberían poner otra criada a su costa ${ }^{116}$. Los familiares o los curadores, al igual que sucedía con los aprendices de los oficios artesanos, se comprometían a traerlas en caso de ausencia para acabar de servir y cumplir las faltas ${ }^{117}$. La justicia también actuaba a favor de los amos encargándose de apresar a las mozas de soldada huidas. Además de por la ruptura contractual, la joven podía ser denunciada por llevarse el vestido que había recibido por adelantado a costa de su soldada ${ }^{118}$. Las leyes dictaminaban igualmente que quien se despidiese no podría servir a otro señor en el mismo lugar sin

112 El procurador de ella afirmaba respecto a la remuneración que qualquier moça que sirba de fuera gana co[mo] cien reales demás de la comida y donde hay estudiantes gana doçe ducados y sirviendo dentro de todo lo necesario gana mucho más... A.H.D.Sa. Leg. 6-27. 5-V-1605.

113 SARASÚA, C.: Criados, nodrizas y amos. El servicio doméstico en la formación del mercado de trabajo madrileño, 1758-1868, Madrid, Siglo XXI, 1994, p. 213.

114 El maestro Sebastián de Vivanco exigió a sus lacayos Alonso Rodríguez y Pedro Conde y a su criado Francisco Herrera, a la vez estudiante de la Universidad, un fiador porque estuviese cierto y seguro de que todos los bienes y aparejos de mulas y otras cosas que le fuesen entregados daría cuenta de ellos cada vez que se lo requiriese y a devolverle los maravedies y bienes que le fueren entregados por el dicho maestro. Jorge Álvarez, clérigo portugués, puso a un tal Jorge Martín al servicio del cedacero Pedro Muñoz. Cuando éste último le demandó un fiador, el eclesiástico respondió que el moço era muy bueno y muy honrado y que le podía recibir muy bien, que él le fiaba que no le haría nada de su casa menos que le fiaba en mil ducados. Lo tuvo tres semanas en su casa, lo envió con una jumenta alquilada a Alba y a Piedrahíta, con mercancías del negocio por valor de 600 reales. Desapareció con todo y el clérigo acabó con sus bienes embargados. A.H.P.Sa. P.N. Leg. 3734. 11-IV-1602. Fols. 339-340; Leg. 3888. 3-III-1607. Fols. 5-6; Leg. 5470. 18-IV1616. Fols. 1008-1009, 1065-1066 y 1068-1069; A.H.D.Sa. Leg. 26-128. 23-VI-1625.

115 A.H.P.Sa. P.N. Leg. 3885. 14-XI-1602. Fols. 87-88.

116 A.H.P.Sa. P.N. Leg- 5570. 21-XI-1608. Fol. 837; Leg. 3891. 9-IX-1619. Fol. 763; Leg. 2966. 18-XI-1612. Fols. 1868-1869.

117 A veces tras el regreso de la criada se podía firmar un nuevo contrato por el cual se comprometía a servir el tiempo que le faltaba. Así sucedió con la gallega Dominga González quien acordó acabar de cumplir los cuatro meses que le restaban a cambio de 8 ducados. A.H.P.Sa. P.N. Leg. 4339. 27IX-1617. Fol. 565; Leg. 4351. 19-VII-1625. Fols. 831-832.

118 A.H.P.Sa. P.N. 3535. 4-XI-1634. Fols. 789-790. 
consentimiento de su antiguo amo ${ }^{119}$. En caso de contravenirlo sería apresado por veinte días y castigado a un año de destierro del lugar. El que lo recibiese como criado se arriesgaba a una multa de 6.000 maravedíes. No obstante, podía abandonar su servicio para aprender un oficio o trabajar para otra persona de fuera del lugar, salvo si había percibido algún adelanto ${ }^{120}$. Para evitar el trasvase de criados de unos amos a otros las leyes castigaban con pena de cárcel el recibir a un mozo de servicio huido. En los protocolos notariales encontramos cartas de protesta de los afectados ${ }^{121}$.

Los curadores de los menores, generalmente procuradores del número, podían solicitar, en determinadas circunstancias, la nulidad del contrato o iguala ante la justicia real de la ciudad y asentar de nuevo al menor con quien "más útil y provechoso le fuese", previa notificación al antiguo amo ${ }^{122}$. Entre esas situaciones estaban los malos tratos, las que daban lugar cierta alarma social o a posibles amancebamientos. El procurador y curador de Catalina García de 17 años de edad, afirmaba que “... la dicha menor [se] asentó a serbir con Andrés González, tendero, y habrá que le sirbe quatro meses, poco más o menos; y al tiempo que le enpezó a serbir era casado y belado con Catalina Hernández, su muger, la qual habrá que murió quinze días, poco más o menos, y el dicho Andrés González, al presente está biudo y es honbre mozo y la dicha mi menor de edad de diez y siete años, donzella honesta y recogida, la qual se teme del dicho su amo, por las raçones dichas, que si está en su serbiçio podría peligrar su honra y honor...". Se requirió al Teniente de Corregidor que diese licencia para asentarla con otra persona sin incurrir éste o la menor en pena alguna ${ }^{123}$. Rara vez se firmó un nuevo acuerdo con el mismo amo tras la huida del joven ${ }^{124}$.

119 Leyes similares se aprecian en otros países como Noruega, donde contratar un criado que hubiese abandonado a su amo estaba penalizado con 100 marcos de multa. En el siglo XVII los sirvientes estaban obligados, además, a notificar su marcha con ocho semanas de antelación. SOGNER, S.: "The Legal Status of Servants in Norway from the Seventeenth to the Twentieth Century", en FAUVECHAMOUX, A. (ed.): Domestic Service..., Op, cit., pp. 180-181.

120 Recopilación de las leyes destos Reynos..., Op. cit., Lib. VI, Tit. XX, Ley I, fol. 196.

121 Entre otras, la de Francisco Capra, mercero, denunciado por un procurador y apresado por el Alcalde Mayor porque admitió y reçivió en su casa a Ysabel, moza, estando igulada con María González, vecina de dicha ciudad. A pesar de alegar que Isabel había sido despedida y que se le había dado licencia para marcharse, no fue liberado en un primer momento ni siquiera ofreciendo fianzas depositarias. A.H.P.Sa. P.N. Leg. 3671. 1-III-1601. Fol. 398 r.; Leg. 5563. Escritura de protesta de Alonso Gómez. cordonero, denunciado por decir había reçivido una moça en su casa en serviçio estando ygualada con San Martín, clérigo. 15-III-1601. Fol. 1224; Leg. 3493. 13-XII-1605. Escritura de protesta de Andrés Lozano, el Mozo, zoguero, y su hermano Juan por decir acogieron a Sedano, mozo, estando igualado con Juan Martín. Fol. 1111.

122 A.H.P.Sa. P.N. Leg. 5089. 16-VI-1603. Fols. 723-724.

123 A.H.P.Sa. P.N. Leg. 3673. 12-II-1606. Fols. 291-292.

124 En el caso de Pedro Rodríguez, quien se había marchado sin cumplir año y medio de servicio. Esta circunstancia se dio porque ya había recibido por adelantado 66 reales del tiempo que le faltaba y se encontraba en un estado de precariedad. La madre afirmaba: porque el dicho mi hijo está sin camisas y 
Aunque lo habitual era recuperar el tiempo de trabajo no realizado por abandono, excepcionalmente se penalizó esta contravención del contrato con la pérdida del tiempo servido y la obligatoriedad de iniciarlo de nuevo; lo mismo sucedía en algunas de las cartas de aprendizaje de los oficios artesanos ${ }^{125}$. En ocasiones los padres se comprometían a la búsqueda del menor ausente, a veces durante un determinado tiempo, como podía ser quince días, o en una circunscripción limitada entre 20 y 22 leguas ${ }^{126}$. Raramente los asientos se rescindían a voluntad de una sola de las partes ${ }^{127}$. El criado actuaba en este sentido como la parte débil del contrato, circunstancia que se aprecia tanto en las condiciones anteriormente citadas así como en el hecho de no percibir indemnizaciones por despido -salvo en casos excepcionales- ${ }^{128}$.

En lo referente a los posibles accidentes laborales ocasionados por el desarrollo de sus tareas, este tipo de circunstancias apenas han dejado rastro. Solamente se ha conservado el testimonio de Alonso Martín de Tordillos quien denunció en un principio a Lorenzo Martín, su amo, vecino de Palacios Rubios, porque le había mandado quitar una gotera de un tejado y se cayó de la escalera descalabrándose la cabeza ${ }^{129}$. Retiró la denuncia exculpándole bajo la declaración de haber sido "caso fortuito". La falta de pruebas y el posible miedo al despido podían actuar como elementos disuasorios a la hora de acusar a los amos.

malparado de bestido, el dicho Alonso de Herrera le ha de dar agora de presente dos camisas de estopa y unos balones y zapatos por qüenta del año y medio que le falta de serbir y si en ello se montare más de lo que ganare haviendo fecho qüenta él, se lo pagaré de mis bienes o el dicho mi hijo se lo desquitará en serbizio que le haya de haçer y porque el dicho mi hijo se le fue de su servicio y agora él quiere bolber a reçebir con calidad de que le haya de dar de presente lo que ba declara[do]. A.H.P.Sa. P.N. Leg. 3270. 23-VIII-1629. Fols. 558-559.

125 A.H.P.Sa. P.N. Leg. 3397. 7-XII-1601. Fols. 233-234; Leg. 5089. 18-V-1601. Fols. 316-317; Leg. 7963. 18-V-1604.

126 A.H.P.Sa. P.N. Leg. 4320. 19-V-1602. Fol. 329; Leg. 7963. 18-V-1604 y 23-VI-1604; Leg. 3999. 10-I-1606. Fols. 502-503.

127 María de Herrera, hija de un hornero, se puso a servir a Catalina Rodríguez, hornera, con la condición de que si la dicha moza no estuviere muy contenta en la casa de dicha Catalina se pueda salir libremente de ella y lo que hubiere servido pagar pro rata. Igualmente el ama podría despedirla si no se hallare bien con ella y en cualquier acaecimiento. A.H.P.Sa. P.N. Leg. 5891. 31-X-1640. Fol. 927.

128 Antonio García, mozo de mulas del racionero Antonio Flórez Moreno, acordó con su amo que en caso de ser despedido por pesadumbres que tuviese con él o con su gente le pagaría sólo a rata de lo que hubiera ganado o le devolvería lo que hubiese cobrado de más. Las ausencias por enfermedad o faltas se le descontarían también proporcionalmente a su sueldo. En determinadas zonas de Holanda -Groningen-, en el siglo XVIII, el criado que se marchaba perdía su salario -se solía cobrar al final del contrato- y debía abonar medio año de salario al comité local de ayuda a los pobres. El amo que despedía a un criado le abonaba seis semanas de salario extra. Domingo Alonso, entró al servicio de Melchor Criado, alcalde de la cárcel real, como mozo de mulas, para ensillárselas y hacer lo demás que fuere necesario en las dicha mulas como lo demás que fuere en su casa y le fuere ordenado por él y su mujer. En el supuesto de ser despedido sin causa se le indemnizaría con un año entero de salario fijado en 150 reales. A.H.P.Sa. P.N. Leg. 5711. 27IV-1633. Fols. 1050-1051; Leg. 5482. 9-I-1625. Fols. 413-414. PAPING, R.: “Oferta y demanda de criados rurales en Holanda, 1760-1920. El caso de Groningen”, Historia Agraria, 35, 2005, p. 120.

129 A.H.P.Sa. P.N. Leg. 4977. 11-III-1613. Fol. 970; JÍMENEZ JURADO, Ma . I.: "El trabajo infantil femenino: un caso de similitud entre los siglos XVI y XX”, en MARTÍNEZ SAN PEDRO, Ma de los D.: Los marginados en el mundo medieval y moderno, Almería, 2000, p. 153. 


\section{d) El trato hacia las criadas.}

En lo que concierne al trato hacia las criadas - no incluimos las relaciones personales ni los legados a la hora de la muerte, objeto de otro estudio-, éste resulta difícil de rastrear, sobre todo a través de los contratos ${ }^{130}$. Sin embargo, el hecho de que un 10 por ciento de éstos requiriesen por escrito que la joven fuese tratada honestamente -se le diese "vida razonable"- es síntoma de que la violencia, la falta de pago puntual o la percepción en las remuneraciones de vestidos de calidad inferior a los pactados pudieron estar a la orden del día ${ }^{131}$. Sirva, como ejemplo del maltrato, el testimonio del procurador de Isabel Méndez, quien declaraba sobre el tío de ésta, a quien había estado sirviendo, lo siguiente: “... Y niego la tuviese para enseñarla, ni tal se probará sino como a una criada, que la castigaba con palos como a tal, no se haciendo lo que quería de manera que la veçindad la tenía lástima de lo que padecía..."132.

En el caso de otras jóvenes que abandonaron a sus amos se decía que era “... porque como a moça bozal no le daba lo que mereçía y la hazía trabaxar mucho y la maltrataba; o porque le tratava muy mal de obra y de palabra sin la alimentar y cumplir con lo que tenía obligación..."133. Pocas de estas situaciones llegaron a los tribunales. Además del citado -referente a Isabel Méndez-, hemos localizado el de Francisco Sequeira quien se querelló de su amo don Gregorio de la Vega, beneficiado del dicho lugar, “... sobre decir haberle dado con un machado un golpe en la cabeza de que le salió mucha sangre..."134. Acabó retirando la denuncia.

La literatura también ofrece testimonios sobre el trato que se debía dar a los criados. Fray Luis de León en su obra La Perfecta Casada declaraba lo siguiente: “... Y no quiero decir que todo ha de ser blandura y regalo, que bien vemos que la buena orden pide algunas veces severidad, mas porque lo ordinario es pecar los amos en esto, que es ser descuidados en lo que toca al buen tratamiento de los que los sirven por eso hablamos dello, de cómo los han de ocupar porque eso ellos se lo tienen a cargo..." 135 .

130 Raffaella Sarti subrayaba en un reciente artículo que se observaba en los estudios sobre testamentos cómo los legados de los amos a los criados no fueron raros. Giovanna Benadusi indica que estas mandas forzaban a los señores a reconocer pública y legalmente el valor no reconocido de su servicio y el honor de su profesión como mujeres trabajadoras. SARTI, R.: "Criados, Servi, Domestiques, Gesinde, Servants: for a Comparative History of Domestic Service in Europe (16 th-19th centuries)", Obradoiro de Historia Moderna, 16, 2007, p. 38; BENADUSI, G.: "Investing the Riches of the Poor: Servant Women and their Last Wills", The American Historical Review, 109, 2004, pp. 824.

131 Esto sucedía a pesar de insertarse cláusulas del estilo: la tratará bien, conforme se trata [a] otras moças de serviçio en la ciudad de Salamanca.A.H.P.Sa. P.N. Leg. 5089. 18-V-1601. Fols. 316-317; leg. 4340. 5-VI-1618. Fols. 632-633.

132 A.H.D.Sa. Leg. 6-27. 5-V-1605.

133 A.H.P.Sa. P.N. Leg. 5287. 8-X-1619. Fols. 335-336; Leg. 4888. 7-VI-1623. Fols. 1274-1275.

134 A.H.P.Sa. P.N. Leg. 3286. 12-X-1641. Fol. 460.

135 Mariló Vigil también ha constatado que los moralistas hacían recomendaciones a las casadas para que tratasen bien a los criados y que en el teatro aparecen algunos que se quejaban de su infortunio y del mal trato que recibían aunque desconoce si era así en la práctica. LEÓN, Fray L. de: La Perfecta 
También los contratos dejan traslucir cierta desconfianza de los amos hacia sus sirvientes. Trataron de salvaguardar la integridad de sus propiedades frente a sus criados obligándoles a ofrecer fiadores o a prometer en el contrato - en uno de cada cinco casos- que no les hurtarían, o como se expresa en las fuentes, sin "hacerle de menos cosa alguna"136. En tales circunstancias, o si por culpa o negligencia de la criada, “... se perdiere cosa alguna o faltare, lo que ansí baliere se ha de poner por qüenta del dicho salario o se la pueda executar en sus bienes..."137. No se trataba de una simple presunción. Por este hecho algunos criados vieron la cárcel y acabaron desterrados ${ }^{138}$. Antonio Arias, beneficiado de San Cristóbal de la Cuesta, se querelló de Pedro Macías porque éste “... había comprado cierto trigo y garrovas y otras cosas de unos criados del dicho otorgante que se lo habían hurtado y que él lo había encubierto..."139. A veces estas sustracciones salían a relucir en las últimas voluntades de los criados ${ }^{140}$. Tal vez los inventarios de bienes realizados por algunas criadas a la hora de entrar a servir a sus amos tuviesen la finalidad de dejar claro cuáles eran sus pertenencias para evitar desavenencias sobre la propiedad de determinados bienes que pudiesen reclamar una $\mathrm{u}$ otra parte ${ }^{141}$. G. K. Brunelle interpreta la inserción de bienes de los criados en las casas de sus amos como un elemento que servía de garantía para que aquéllos completasen honestamente y de manera íntegra su servicio ${ }^{142}$. Sea una u otra la interpretación, en cualquier caso, el hecho constituyó un claro síntoma de mutua desconfianza.

\section{Consideraciones finales}

Las escrituras contractuales salmantinas manifiestan, en síntesis, un modelo de servicio urbano en el que predominó la presencia de féminas menores de edad -fun-

Casada, Madrid, Taurus, 1987, p, 126; VIGIL, M.: La vida de las mujeres en los siglos XVI y XVII, Madrid, Siglo XXI, 1986, p. 125.

136 A.H.P.Sa. P.N. Leg. 3999. 10-I-1606. Fols. 502-503.

137 A.H.P.Sa. P.N. Leg. 3891. 26-X-1619. Fol. 762; Leg. 4362. 28-X-1630. Fols. 277-278.

138 El boticario peñarandino Faria denunció a su criada Jerónima Hernández porque estando en su serviçio le havía hurtado ciertas madejas y manitas y sábanas y otras cosas. Se la apresó en la cárcel real y se la soltó con la condición de que no volviese al lugar de Peñaranda. El Teniente de Corregidor amplió su destierro a toda la circunscripción de Salamanca. Se vio obligada a aceptar la condena por ser pobre y estar en la dicha cárcel comiendo de la limosna de los pobres della y no poder haçer su descargo. A.H.P.Sa. P.N. Leg. 4321. 17-VII-1603. Fol. 924.

139 A.H.P.Sa. P.N. Leg. 4699. 28-VI-1618. Fol. 1998.

140 Agustina de Benavides, en servicio de don Antonio Maldonado, caballero del hábito de Santiago, le demandó por lo que le debía de su salario. Se marchó de casa, sacó un jubón que valía 28 reales y lo vendió para sus necesidades. Declaraba que su amo no la debía nada, que la perdonase o se pagase dicha cantidad. A.H.P.Sa. P.N. Leg. 4181. Año 1646. Fols. 792-793.

141 A.H.P.Sa. Leg. 2975. Inventario de los bienes que Catalina García llevó en poder de su ama. Leg. 2975. Fol. 1535; Leg. 3762. Inventario de los bienes de Ana Sánchez cuando entró en servicio del racionero Juan Rodríguez. 8-II-1623. Fols. 483-484.

142 BRUNELLE, G. K.: Op. cit., p. 380. 
damentalmente entre 15 y 25 años, como en Europa-, solteras, sometidas a contratos de corta duración -anual-, con un carácter precario, como aconteció en otros lugares de la geografía española ${ }^{143}$. No obstante, perviven todavía tendencias bajomedievales como la inserción en el hogar de niñas muy pequeñas para la realización de labores domésticas. Este claro predominio de la mujer contrasta con las cifras que nos ofrecen los censos para la ciudad en la centuria anterior y se manifiesta más acorde con lo sucedido en otras ciudades europeas (Murcia, Venecia, Varsovia, entre otras).

Bajo estas circunstancias de temporalidad difícilmente se puede hablar en la mayoría de los casos de creación de vínculos familiares entre amo-criada o de la consideración de esta última como parte de la familia ${ }^{144}$. Enrique Villalba ha señalado que salvo los criados de mayor rango, que llegaban a gozar de una cierta familiaridad con los señores, con los más humildes se mantuvieron las distancias, salvaguardando un orden social avalado por las leyes ${ }^{145}$. Esta relación tan distante cambia si tenemos en cuenta el análisis de los testamentos -objeto de un futuro estudio-, donde se expresa una mayor confianza en los señores quienes son nombrados en numerosas ocasiones como albaceas e incluso llegaron a convertirse en herederos de sus criadas.

Por otro lado, no parece tampoco, excepto en las mujeres con asientos laborales de larga duración, que la vinculación de éstas al mundo laboral respondiese al deseo de conseguir acumular un pequeño capital -llámese dote- o un ajuar de cara al matrimonio ${ }^{146}$. Éste ha sido uno de los objetivos subrayado por diferentes estudios tanto extranjeros como españoles. Estrella Garrido observa a través de los contratos matrimoniales donde la mujer se dota a sí misma, cómo la mayor parte de esta dote, cuando no su totalidad, provenía del servicio doméstico. En Salamanca fue más bien la búsqueda de manutención y vestido, es decir, el poder cubrir las necesidades básicas primarias,

143 Eduardo Montangut habla de cómo en Madrid las criadas y nodrizas vivieron situaciones similares en el siglo XVII. MONTANGUT, E.: "Criadas y nodrizas en la Casa Real. Sus recompensas: varas de alguaciles de la casa y corte", Torre de los Lujanes, 20, 1992, p. 76.

144 Estaríamos, como ha subrayado Julio Rodríguez, y previamente J. A. Maravall, ante el criado moderno el cual no se considera unido al amo por un vínculo que trascienda el deseo de provecho. RODRÍGUEZ LUIS, J.: “Guzmán, criado impenitente, criado perfecto: el servicio doméstico en la picaresca”, Revista Internacional de Sociología, 41, 1983, p. 278.

145 VILlALBA PÉREZ, E.: "Oficios humildes y marginación en el Madrid de los Austrias", en CASTILLO, S. (coord.): El trabajo a través de la Historia, Madrid, Asociación de Historia Social, 1996, p. 182.

146 En Castellón, en el siglo XVI la soldada de la joven, en ciertos contratos, era susceptible de ser percibida por su futuro marido. GARRIDO ARCE, E.: "El trabajo de las mujeres en la economía familiar preindustrial. La huerta de Valencia en el siglo XVIII", en RAMOS, Ma . D. y VERA, Ma. T. (eds.): Op. cit., tomo I, p. 110; ROMANO, D.: Op. cit., 155; APARICI MARTÍ, J.: “Aprender un oficio y servir. Perspectivas laborales para los jóvenes del Alto Palancia en el siglo XV”, Boletín de la Sociedad Castellonense de Cultura, tomo LXXXIII, 1997, p. 491; LASLETT, P.: "Servi e servizio nella struttura social europea", Quaderni Storici, tomo LXVIII, 1988, p. 347. 
lo que condujo a las jóvenes a integrarse en trabajos donde, bajo la perspectiva actual y no tanto bajo la paternalista de entonces, fueron sometidas a una dura explotación -amplios horarios de trabajo, discrecionalidad del amo a la hora de señalar las tareas, escasa o nula atención médica, leyes que penalizan la ausencia de los sirvientes-. Ser criada, al menos para mayoría de las contratadas en este período, constituyó fundamentalmente un trabajo ocasional o una vía laboral, tal y como han apuntado estudios sobre otras zonas -caso de Galicia- y no tanto una forma de vida ${ }^{147}$.

147 Angelina Arre indica para el caso italiano que para muchas mujeres el servicio doméstico no actuó como una fase provisional de la vida o un período previo al matrimonio sino como un refugio en épocas difíciles de la existencia. DUBERT, I.: Historia de la familia ..., Op. cit., p. 80; RIAL GARCÍA, S.: "El servicio doméstico...., Op. cit., p. 313, ARRU, A.: "Servi e serve: le particolarità del caso italiano", en BARBAGLI, M. y KERTZER, D. I.: Storia della famiglia italiana. 1750-1950, Bolonia, Il Mulino, 1992, p. 275. 